\title{
Masculinity, reading and the school library: Smoothing the abrasive rub
}

\author{
By
}

Anne Virginia McLean

Submitted to the School of Information Management, Victoria University of Wellington in partial fulfilment of the requirements for the degree of Master of Library and Information Studies

June 2005 


\section{Acknowledgements}

With grateful thanks to all the school librarians who took part in this study for sharing their time, knowledge, enthusiasm, opinions and experiences.

To my supervisor, Dr Chern Li Liew, many thanks for your encouragement, support and counsel.

My sincere gratitude to Lynley Stone, the Auckland tutor, for her unfailing enthusiasm and guidance over the past three and a half years.

Thank you to my family, Peter, Ellen and Celia for giving me the space to do this, I know it has not been easy for you. 


\section{Table of Contents}

Acknowledgements

Abstract

List of Figures and Tables

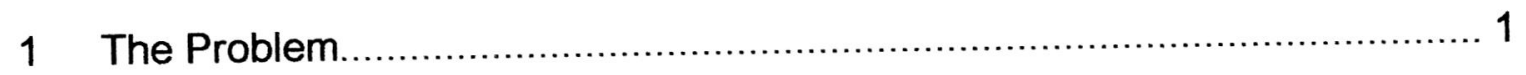

1.1 The problem statement ............................................................. 1

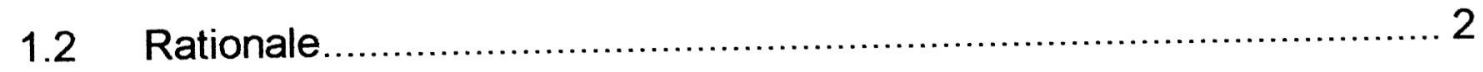

1.3 The research question ............................................................ 3

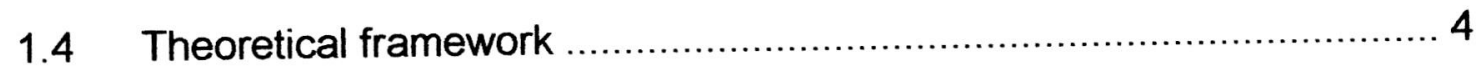

1.5 The role of the researcher........................................................ 4

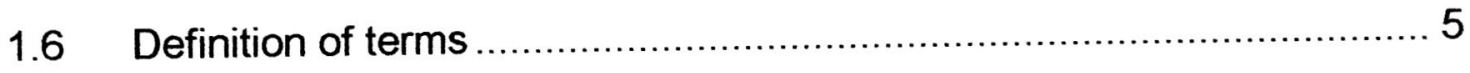

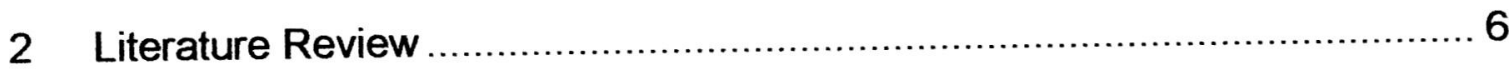

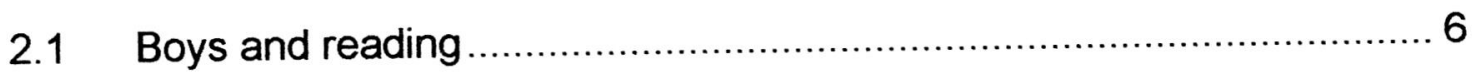

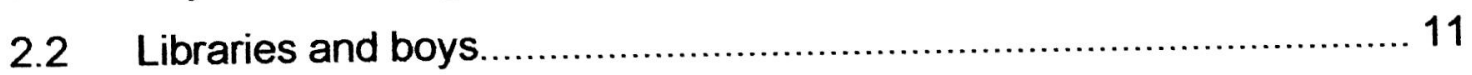

2.3 Conclusions .................................................................... 14

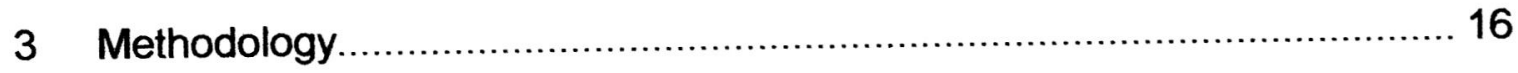

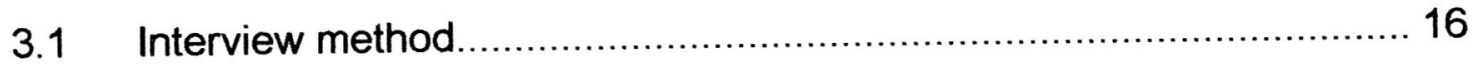

3.2 Development of the questionnaire and interview questions ............... 17

3.3 Delimitations and limitations................................................. 18

3.4 Human Ethics Committee ...................................................... 19

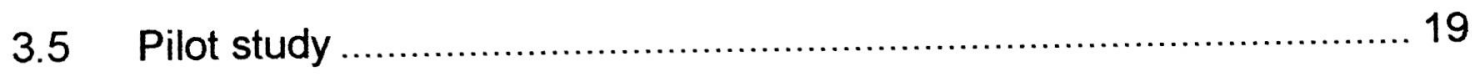

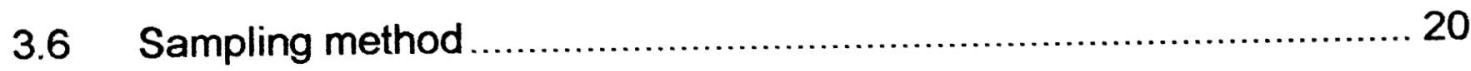

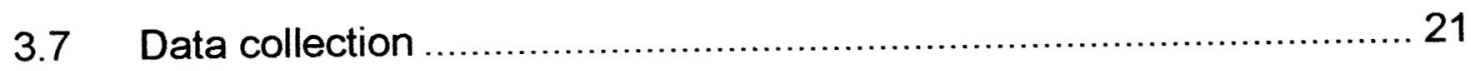

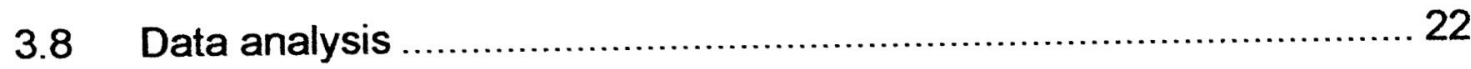

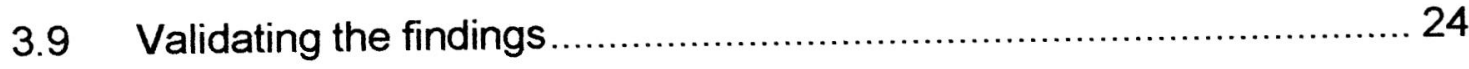

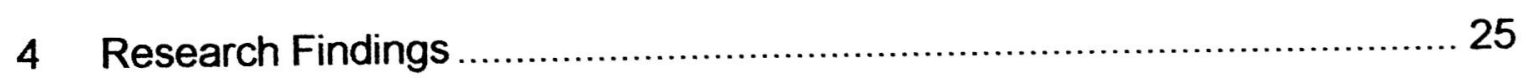

4.1 Demographic profile of the participants and their schools................. 25 


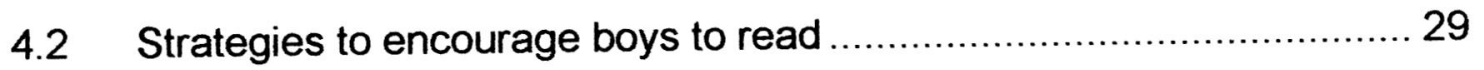

4.3 Influences on boys' attitudes and behaviour in the library................... 43

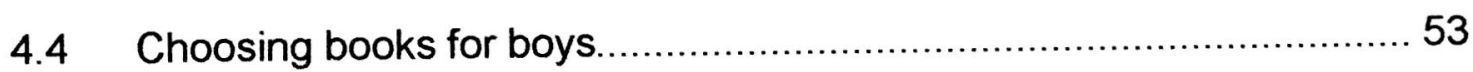

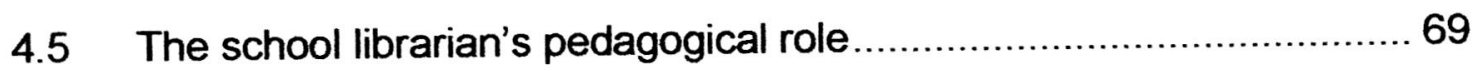

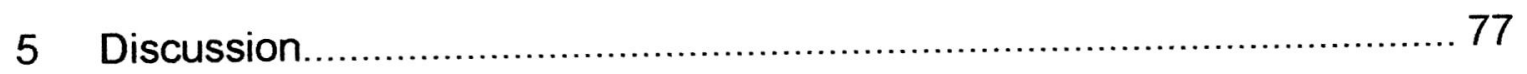

5.1 Strategies to encourage boys to read ……….................................. 77

5.2 Influences on boys' attitudes and behaviour in the library................... 79

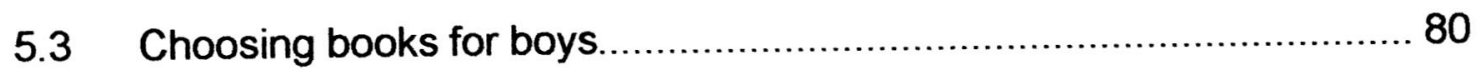

5.4 The school librarian's pedagogical role ........................................... 84

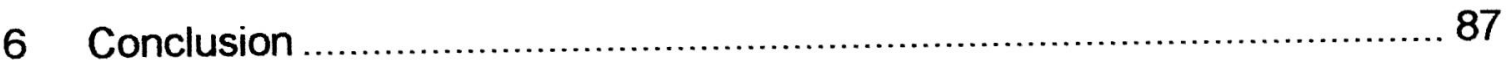

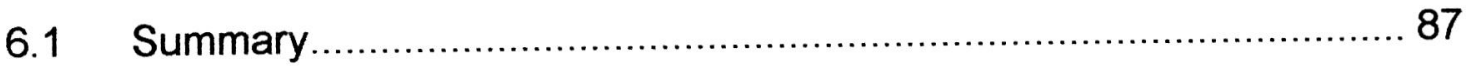

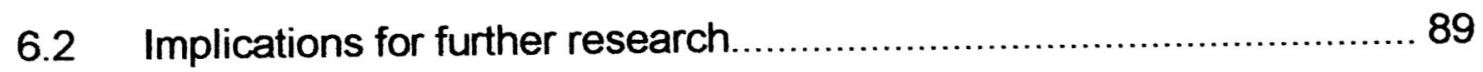

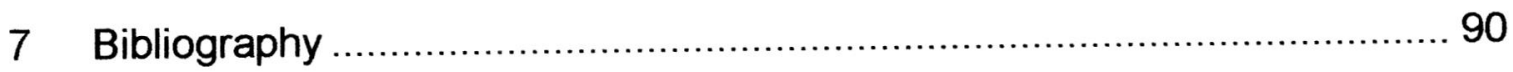

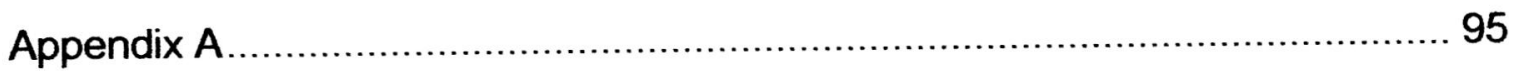

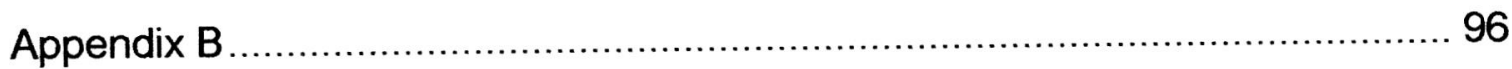

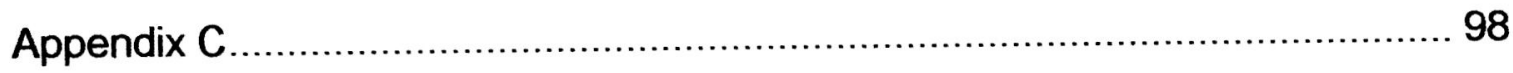

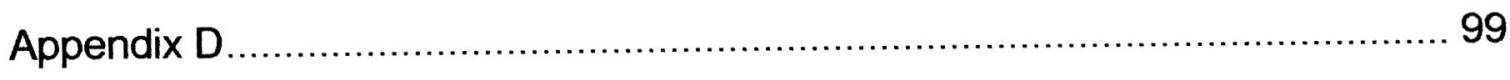

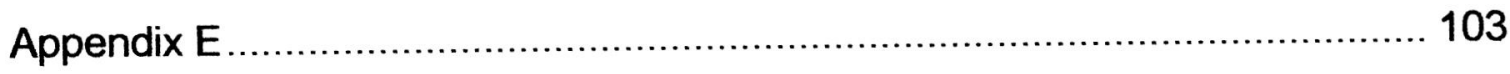

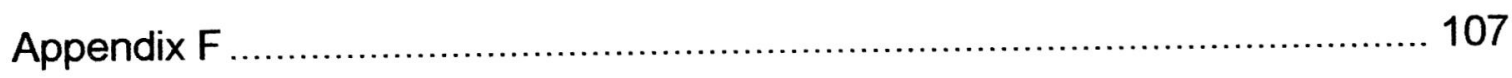

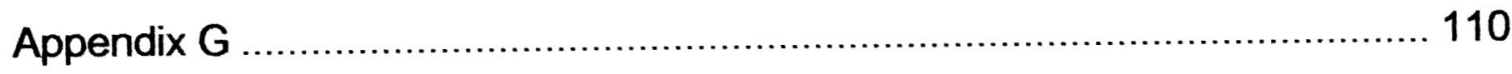




\section{List of Figures}

\section{Figure}

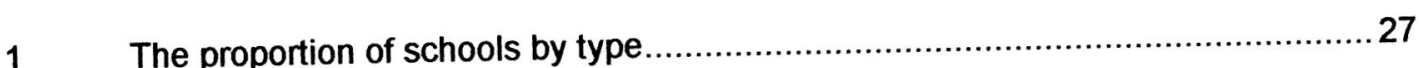

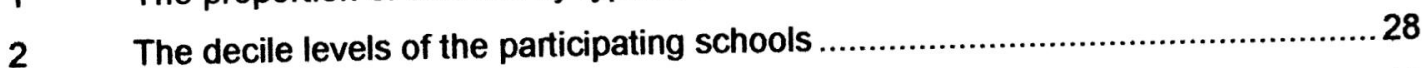

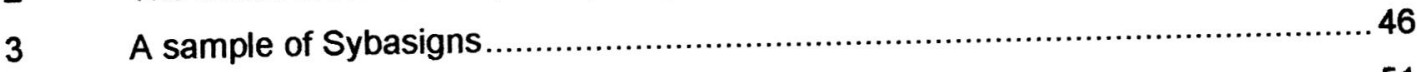

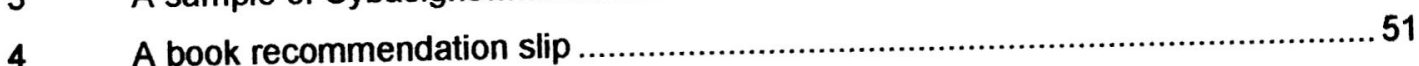

5 Dacked!

Alpha Force: Hostage

$7 \quad$ Remembrance

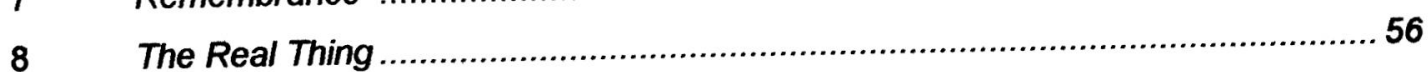

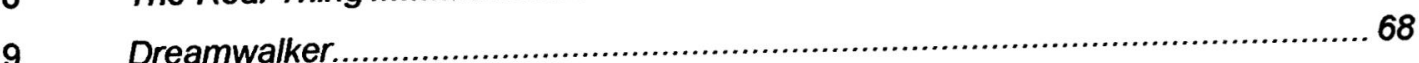

\section{List of Tables}

Table

1 The questionnaire and corresponding research subquestion numbers ..................17

3 Journals referred to by the participants............................................................... 40

$4 \quad$ Organisations referred to by the participants........................................................ 41

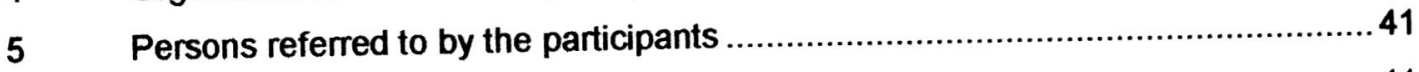

$6 \quad$ Web sites referred to by the participants ............................................................. 41

$7 \quad$ Methods used to assist students locating a book ................................................43

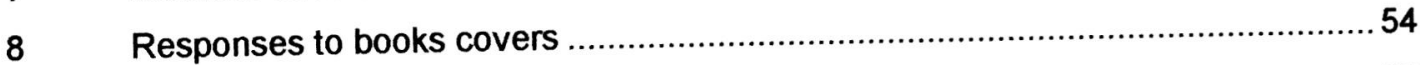

$9 \quad$ Preferred fiction genre - primary and intermediate schools................................58

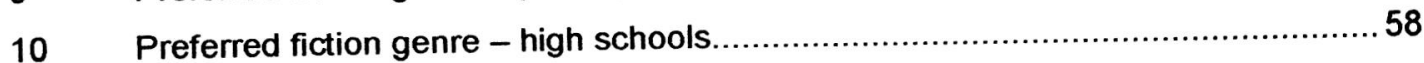

11 Favourite reads - primary and intermediate schools ........................................61

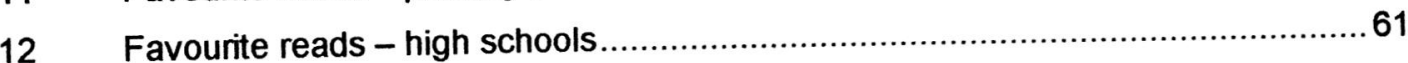

13 Boys' preferences for fiction versus non-fiction ..................................................64

14 Departments or personnel who support the librarian motivating boys to read .........72

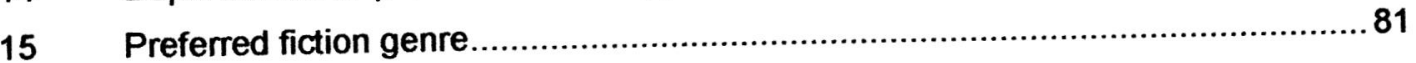




\section{Abstract}

During the 1990s, governments and the education profession noticed that boys were lagging behind girls academically. Reading, or the lack or it was pinpointed as a major cause and it was observed in an Auckland high school library that significantly more books were issued to girls than boys over a six month period in 2004 .

The purpose of this study was to achieve a deeper understanding of how a purposefully selected sample of school librarians has successfully encouraged boys to read. A qualitative approach was employed using two methods of data collection: a questionnaire to gather largely statistical data and in-depth interviews to gather data about participants', experiences, knowledge and opinions.

The study found that school librarians use a variety of strategies to promote reading to boys. A school library needs to be well stocked with a wide range of current, appealing, reading materials as boys are discerning, hybrid readers. Knowing the students and the library collection was central to matching boys with books and the library needs to be more than a book repository.

It is concluded that Ranganathan's 'Five laws of library science' are still applicable today in the school library and school librarians need to be a professional, visible and approachable presence in the school.

\section{Keywords}

[reading] [reading - promotion] [boys - books and reading] [masculinity] [school libraries] [school librarians] 


\section{The Problem}

\subsection{The problem statement}

A review of circulation statistics for an Auckland high school library revealed that between March 2004 and September 2004, 200\% more books were issued to girls than boys. Is this phenomenon isolated to this particular school or is it mirrored in other schools? A review of educational and library literature and the popular press reveals that it is indicative of national and international concerns about boys' reluctance to read which is affecting their academic ability and emotional stability.

In the 1990s governments and the education profession noted that boys were lagging behind girls academically. This has been documented in many countries. In the United States, Smith and Wilhelm (2002) cite multiple studies where boys fall behind girls in literacy tests. In Australia, Cresswell et al (2002) list boys' reluctance to read and their increased use of videos and computers as the major factors contributing to their underachievement.

In New Zealand the situation is no different, an Education Review Office (ERO) report (1999) summarises the situation, 'girls outperform boys at school against most measures of achievement.' English is highlighted as the subject with the greatest gender difference in achievement. The implications of boys' underachievement, the report continues, is that boys are more likely than girls to leave school with no qualifications which will have serious consequences for society as a whole. Looking at this argument from the perspective of a knowledge economy, literacy skills are essential. The 2001 international study, The Progress in International Reading Literacy Skills (PIRLS) (Mullis et al 2003) found that New Zealand has one of the largest gaps in reading skills between boys and girls among the 35 countries surveyed. It is the girls who are reading significantly better than the boys. 
Considering the problem of boys underachieving is not isolated to a specific country but reported worldwide, Brozo's (2001, p. 318) claim that boys are in an 'academic tailspin' has substance.

To focus on boys' academic underachievement and information literacy skills is too narrow, Reed (1999) and Brozo (2001) list statistics identifying behavioural problems, reading disabilities, crime, violence, suicide, drug and alcohol addictions are predominantly male problems.

The benefits of reading for both educational and emotional needs are well documented in the literature. Eyre (2003) provides an overview of the role of reading and its importance to the young people of today. While information literacy is the literacy of the moment Eyre (2003) makes the observation that to master and use digital technology requires proficient reading skills and too much emphasis has been placed on the technology. Eyre (2003), Meiers (2004) and Usherwood and Toyne (2002) all highlight the importance of imaginative literature in children's development and it is succinctly summarised by Usherwood and Toyne, 'reading forms and informs the developing self ( $p$ 40).

\subsection{Rationale}

The bulk of the research investigating boys' reading is conducted by the education profession and focuses on improving classroom teaching skills. Goodin (2004) attended a course to improve students' reading comprehension and was the only librarian among 100 teachers. Goodin (2004) believes school librarians 'are the missing, underappreciated link in the effort to help all students achieve in reading' (p. 13).

A study by Wicks (1995) illustrates that school libraries have been successful encouraging boys to read, but does not report how this was achieved. Much of the research into school libraries and boys' reading are 'in-house' research projects and the resulting strategies work for that particular school but may not be applicable for another school. The school librarian often conducts the research. For example Gordon-Hall 
(2002) concludes from her research that the results are inconclusive due to the small sample and the school demographics are quite different from other schools. In New Zealand, Southland Boys High School (Stewart 2001) was awarded the 2001 LIANZA $3 \mathrm{M}$ award for innovation in libraries for their 'whole school literacy project'. However it is concluded that the project was specifically developed for a boys-only high school and may not be so successful in co-educational schools where boys tend to lag behind girls academically. It is also commented that adaptations would need to be made for it to work in a primary school. As a result of her study, Simmons (2001) introduced a number of changes to the school library but the study is isolated to one school with its own particular culture. A school case study into boys' reading in Australia (Barry and Meiers 1998 ) includes lists of recommendations for the school library, but librarians are not interviewed.

This research project will approach the same problem from a different perspective. Several schools with varying demographics will be involved in the study and the school librarians will be interviewed with the purpose of building a consensus of ideas of how school libraries can encourage boys to read. Doiron and Davies (1996) concluded from their study of school libraries in Canada that successful programmes developed by school librarians should be made known to other librarians, which is what this research aims to do. In a survey of school libraries and research, McNicol (2003) states that several school librarians thought that research identifying strategies to encourage boys to read would be valuable and this project aims to collate ideas and themes from which strategies can be developed.

\subsection{The research question}

The main research question is:

How can school libraries encourage boys to read?

As stated in Creswell (2003 p. 106) qualitative research 'states research questions, not objectives' and therefore subquestions are included in this study not objectives. 


\subsubsection{Subquestions}

1. What strategies and initiatives have school librarians developed to encourage boys to read?

2. What are the influences on boys' attitudes and behaviour when they are in the library selecting and reading a book?

3. What do school librarians consider when choosing books for boys?

4. What do school librarians perceive to be their pedagogical role?

\subsection{Theoretical framework}

The theoretical framework is firmly embedded in the theory of masculinity as a social construct. The notion that 'boys are in trouble, both in school and out' (Smith and Wilhelm 2002, p. 4) has led to an increase in discourses on theories of masculinity. The theory that masculinity is a social construction formed by the values and influences of the society in which men live and what it means to be male will evolve as the society redefines and changes is supported by Gilbert and Gilbert (1998) and Smith and Wilhelm (2002.) This construct of masculinity is not static, it is dynamic and diverse (Gilbert and Gilbert 1998.) Smith and Wilhelm (2002) conclude that this theory has more power for them as teachers than the theory of biological determinism that is prominent in the popular press. Biological determinism diminishes and constricts masculinity, lowers behavioural expectations and excuses failure (Gilbert and Gilbert 1998). A library operating under the framework of social construction will see book selection among children and adolescents as a fluid changing social construct not a static construct.

\subsection{The role of the researcher}

As noted in Creswell (2003) it is important in qualitative research to identify the bias and preferences of the researcher. The nature of the research involves interpretation by the researcher and personal values may influence the interpretive process. 
The researcher's view is that masculinity is a social construct as discussed in the theoretical framework and comments during the interview process such as 'boys will be boys' will be noted with negative reflection. Adolescents; male and female are regarded as much maligned and the researcher has no negative preconceptions towards them. It was the school library the researcher works in that recorded the low rate of book issues to boys so there is a personal interest in this study and it is regarded as a learning experience. Finally, the researcher supports the views of Coles and Hall (2002) that strategies to encourage boys reading should not simply 'pander' to boys and Young (2001) that measures to improve boys' literacy skills should not compromise or punish girls.

\subsection{Definition of terms}

Decile level refers to the socio-economic rating scale (1-10) applied to New Zealand state schools. Level 1 is the lowest socio-economic rating and level 10 the highest.

Reading in the context of this study means leisure reading encompassing magazines, fiction and non-fiction reading for hobbies, sports and general interests.

Boys reading or boys' reading. The literature is confusing on this issue and it appears the term 'boys reading' has now become a cliché impervious to grammatical rules. In this proposal the term boys reading has been considered in the context of the sentence and if it is a simple possessive, an action belonging to the boys, an apostrophe has been used. 


\section{Literature Review}

The literature comes from library and information science (LIS) and education databases, journals and books. This review investigates the influences on boys' reading, what boys would prefer to be doing and what boys like to read. From a library perspective the review focuses on libraries and youth, school libraries and academic achievement and school libraries encouraging boys to read.

\subsection{Boys and reading}

\subsubsection{Influences on boys' reading}

Alloway and Gilbert (1997) conclude from their review of Australian studies on boys and literacy that it is often influenced by a combination of factors rather than a single factor. The most significant influences are:

\section{- Masculinity}

Boys' conceptions of what it is to be male influence their attitude to reading. Martino (1998) interviewed adolescent boys about their perceptions of English and concluded that boys perceive reading to be feminine and contradictory to their perceptions of what it is to be masculine. Martino also advocates encouraging boys to read texts that portray males beyond traditional stereotypes, masculinity diversified while Brozo (2001) argues in the context of the social problems afflicting boys that it is better they read anything rather than nothing.

\section{- Academic ability}

Moffitt and Wartella (1992) and Holden (2002) agree that children of higher academic ability are more likely to read. Holden reports, in her study from the United Kingdom that students of low academic ability rated English as their least favourite subject while students of higher academic ability rated it third favourite. 


\section{- Socio-economic}

Socio-economic status has a bigger impact on literacy achievements than gender. The results of Masters (1997) survey showed girls were more likely to achieve a target reading standard by 11 percentage points over boys. However students from high socioeconomic backgrounds favour students from low socio-economic backgrounds by 26 percentage points and the difference increases in later years. The effect is then cumulative, as Gambell and Hunter (2000) point out males from a low socio-economic background are less likely to achieve academically than females from the same environment.

\section{- Family}

Love and Hamston (2001) identify that fathers substantially contribute to the development of sons who are committed readers. Initially fathers serve as the role model and as the boys mature the relationship is one of partners reading and discussing books and magazines with each other. The importance of fathers who read is reinforced by Gambell and Hunter (2000) who believe boys reject reading because reading is perceived as a female activity associated with their mothers as they develop their own male identity. Pottorff et al (1996) confirms that mothers are the main readers in a family being ten times more likely to read books than fathers.

\section{- Peers}

Simmons (2001) notes from her research that peers have a strong influence on boys' reading and the choice of book. Millard (1997) explains that girls are more likely to regard reading as a social activity and books are swapped and discussed with friends. These social networks or pools then draw other girls into reading. Conversely boys were highly unlikely to discuss or share books with friends, however they did exchange football magazines. Gambell and Hunter (2000) who note that boys are less likely to discuss books with their peers for fear of disapproval and seeming 'uncool' confirm this. 


\subsubsection{Boys' leisure activities}

Simmons (2001), a teacher-librarian at a Scottish high school, states that the large majority of boys in her survey gave sporting activities as their main recreation and is supported by Moffitt's (1992) study of adolescents' leisure reading habits. Boys in this study ranked reading fourth as a leisure activity; sports, being with friends and music being the more popular activities. Also from the survey $65 \%$ of males read for leisure and $85 \%$ of females. Moffitt's survey did not differentiate between consistent and occasional readers therefore the results may be inflated. Smith and Wilhelm (2002) continue the sports theme stressing the importance of activity and being with friends as the most important leisure pursuits for boys, reading was in the last resort activities. A study by Wicks (1995) shows that reading was rated along with sports as one of the most popular hobbies. This study was conducted after school libraries in the area had been actively encouraging fiction leisure reading amongst their male students and Wicks concludes they are doing an 'excellent job' (p. 15).

Coles and Hall (2002) claim that boys see reading as a leisure activity while girls see the educational benefits of reading. Gambell and Hunter (2000) believe girls see reading as a leisure pursuit and boys associate reading with work and business. The difference in opinion may be based on age, Coles and Hall are probably commenting on younger males and females than Gambell and Hunter.

\subsubsection{What do boys read?}

Coles and Hall (2002) replicated a previous survey of children's reading habits for their comprehensive study 'The Children's Reading Project'. The study was conducted in the context of boys' achievements, with the purpose of investigating the wide culture of texts available to young people and how they perceive themselves as readers or non-readers. Coles and Hall confirm that reading choices are highly gendered and the gap increases as children become adolescents. 
Graphic novels, comics and the bright visual appeal of non-fiction attract children and young adults who have grown up in the visually stimulating environment of television and computer games. Dresang (1999) notes that 'children of the digital age are graphically sophisticated' (p. 94) and the 'rhizome book' (Burnett and Dresang 1999) merges the print and digital world.

\section{- Fiction}

Coles and Hall (2002) make the observation that boys read over a wide range of genre. Their study reveals sports-related books as the favourite among boys, however they do not distinguish between fiction and non-fiction for sports books and it can be assumed that they are predominantly non-fiction so therefore are not included as fiction. War and spy-related are then considered the most popular fiction genre for boys while Millard (1997) reports adventure and action stories as the most popular. However, Millard's study also shows the majority of boys did not have a favourite genre seeing them all as 'equally unappealing' (p. 53).

\section{- Non-fiction}

A study in the UK by Moss (1999) observed and documented seven to nine year old boys' reading in and out of school, concludes that boys chose the visually rich non-fiction texts to cover their poor reading skills while remaining equal with peers who are better readers. Simmons (2001) offers a similar perspective believing that boys with reading difficulties preferred to read multimedia than books because the visual images helped them to understand the text.

In an action research project at an Essex high school the school librarian in an effort to raise the academic achievement of boys gave boys a 'book bag' to take home containing a variety of reading material. The least favourite part of the book bag was the fiction titles. However boys preference for non-fiction over fiction is not supported by Hartlage-Striby (2001) who recorded books issued from three school libraries. Although more nonfiction was issued to boys than girls, overall boys read more fiction than non-fiction. 
Unlike Moss (1999), Hartlage-Striby could offer no reason why boys selected more nonfiction than girls. Coles and Hall (2002) develop the theme further illustrating that boys do not exclusively read non-fiction. In their study only a small percentage $(2.8 \%)$ read exclusively non-fiction, however of those who do, $78 \%$ were boys. They conclude that boys are more likely to be in the 'hybrid' category; reading from fiction and non-fiction not because they are poor readers as Moss states but because of their high interest in reading about sports and hobbies.

\section{- Periodicals}

Boys' preference and enjoyment for magazine reading is well documented in the literature. As a result of her study into raising boys' achievement in literacy Simmons (2001) has greatly increased the range of periodicals in the school library. Smith and Wilhelm (2002) conclude from their research that boys are more inclined to read magazines particularly sports magazines supporting the Coles and Hall (2002) observation that boys read magazines and newspapers containing factual and statistical information that relate to their interests and hobbies.

\section{- Comics and graphic novels}

Graphic novels are considered an enticing tool into the literary experience appealing mainly to the visually sophisticated young male (Bruggeman 1997, Smith and Wilhelm 2002). Both Crawford (2002) and Versaci (2001) agree that as well as engaging young readers graphic novels develop analytical and critical thinking skills which relates back to the Coles and Hall (2002) view of boys preference for analytical texts. A study by Ujiie and Krashen (2001) observes that boys 'who read more comic books did more pleasure reading, liked to read more and tended to read more books'. 


\subsection{Libraries and boys}

\subsubsection{Libraries and services to youth}

'Libraries must attempt to meet three major categories of young adult needs: (1) research needs, (2) recreational materials, (3) informational needs (Harmon and Bradburn 1988). In providing these services to young adults Chelton (1985) notes that librarians have set ideals of how adolescents should behave and act, and are uncomfortable when adolescents do not meet these ideals and unfortunately it is most often boys who fail these standards.

Owen's (1998) research into library services to teenagers in New Zealand concludes firstly that teenagers experiences' of libraries are 'mostly negative and contribute to the perception of the library as rigid, rule bound and user-unfriendly' ( $p 70)$. Secondly the layout and design of libraries does not allow teenagers to be teenagers. Teenagers would like to be able to eat in the library and talk together. Rosenzweig cited in Chelton (1985) supports this view stating that adolescents need a place in the library where they can move and fidget, talk quietly with friends and lounge about reading. This creates a difficult situation for school librarians, as the school library is primarily a place of study and research.

\subsubsection{School libraries and academic and reading achievement}

Much of the literature focuses on research investigating the links between school libraries and academic achievement. Research linking school libraries and reading is less common and less conclusive for example Elley's study cited in Lonsdale (2003) concluded that effective reading programmes require a large number of books.

Lance (2002) conducted a series of studies in various American states that are now referred to as the 'Colorado-style studies'. These studies illustrate that academic achievement is higher when school libraries employ qualified staff, the staff are actively 
involved in the teaching and learning environment and the libraries are well stocked with print and digital resources. The Colorado-style studies highlight the need for the school librarian to collaborate with teachers, attend pedagogical meetings and continue their professional development. These findings are confirmed in a study by Todd (2004), however, Todd also comments that while students see the school library as providing the information resources necessary for assignments and research projects they do not see it as providing for their leisure activities and interests.

In 1995 Krashen investigated the relationship between reading ability and school library quality. The result showed a positive correlation between reading scores and the number of books per student and a negative correlation between reading scores and library services. A result Krashen (1995) termed 'puzzling'. Library services included services such as literacy skills instruction, reference assistance and interloans. Krashen (1995) explains that this 'puzzling result' could mean that librarians who offer more services often overlook encouraging reading.

\subsubsection{The role of the school library}

A paper by Loertscher (1990) reviewing reading research in school libraries explains that traditionally recreational reading was the major purpose of a school library and the school librarian's main role was to foster the love of reading. Loertscher continues that the main function of the library has changed to one of supporting the curriculum. Taking note of changing environmental factors during the last twenty years, Slyfield (2001) notes that the main use of primary school libraries in New Zealand is to support reading, but in secondary school libraries the main use is curriculum based. Eyre (2003) argues that school libraries have 'an important role to play in nurturing reading for it's own sake' ( $p$. 224). In a previous study Eyre explains that as school library budgets shrink spending on fiction texts is reduced and funds are diverted to curriculum related materials. As schools invest more funds in online databases the situation can only be exacerbated. School libraries also have a role to play providing reading material for children from low socioeconomic families who have been identified as most likely to have low literacy skills. 
Krashen (2001a) makes the comment that for many of these children the school library is the only source of reading material.

Raftse and Saetre (2004) cite earlier studies in their recent article on school librarians and their pedagogic function. Firstly they observe the Norwegian vision of school libraries, which includes being a place to promote the pleasure of reading as well as a place to actively seek information. Secondly one of the findings from a previous study was that students very rarely used the library except for a small group of 'regulars' who used the library for mainly social purposes. Thirdly there was little communication between teachers and the librarian and the library was perceived to be 'more or less running its own and parallel life to the classroom life of the teacher and student' (p. 113). Finally it is observed that the school librarians were uncertain about the pedagogical aspect of their job and many of the students felt they could not approach the librarians for help in even small tasks such as searching the catalogue. The inference that can be drawn is that if a school librarian is to promote literacy activities they must be a professional, visible and approachable presence in the library and school.

\subsubsection{School libraries and boys' reading}

As referred to previously Wicks (1995) notes that efforts by school librarians to encourage fiction reading amongst boys has been effective, but reports no further details. The research available is peppered with small research projects undertaken by the librarian. Gordon-Hall (2002) conducted an action research project in her school library and admits the data is not reliable. As a result of her study Simmons (2001) implemented schemes to improve boy's reading and a follow up study to report progress would be appropriate.

Although Millard's $(1997,1998)$ research using critical theory to understand the relationship between masculinity and literacy is directed at teachers in a classroom situation, her observations about school libraries are worth noting. Millard (1997) makes the point that boys need more guidance selecting a book to read; during set reading times 
at school they were more likely to come without a book or would re-read a book as it is a safer option than selecting a new title. Millard continues, stating that school librarians should possess a wide knowledge of contemporary children's and young adult literature and get to know the students; their interests, reading levels and reading preferences so they can help select books appropriate for them. Millard (1998) also reports that many of the boys interviewed found school library books to be out-of-date and unappealing.

Following two Canadian studies into children's reading preferences Doiron (2003) asks if school libraries should re-organise their collection, into separate male and female collections combining both fiction and non-fiction. At first dismissed as impossible the idea does have some merit. As boys are less likely to browse the shelves to select suitable reading material school libraries could position a sample of books suitable for boys including fiction and non-fiction in an easily accessible location in the library following the time proven example of department stores who situate mens' clothing at the entrance to the store.

In New Zealand, Southland Boys High School (Stewart 2001) developed a literacy project and for the first time the library became a core component in the school. The key issues from the project were that boys increased and improved reading levels, funds were used to purchase more fiction material, boys could test their own reading levels through library computers.

\subsection{Conclusions}

From the review of the literature it is concluded that boys read over a wide range of genre and do not limit themselves to just non-fiction as has been assumed and that a combination of variables influence their reading practices.

For a school librarian to adopt and implement strategies to encourage boys reading they need to be considered an active professional member of the school community with a clearly defined role. To achieve this the librarian needs to attend pedagogical and curriculum meetings and actively participate in the school as a learning organisation. 
School librarians also need to balance many opposing issues. They need to maintain a focus on reading for academic achievement and emotional stability which is often overshadowed by technological literacy. Collection development funds must be allocated between curriculum materials, fiction and non-fiction interest and hobby books. The fiction funds must be further divided between novels and the 'soft literature' of graphic novels and periodicals. The librarian must decide between purchasing books boys like to read and books they should read. The library needs to be seen as a place for study and research as well as a comfortable environment to unwind and read a book or look for information related to a hobby. What is the compromise between noisy and disruptive behaviour of mainly boys and students who want a quiet place to study? 


\section{Methodology}

The research design was a qualitative inquiry with a phenomenological approach. Leedy (1997, p.104) describes qualitative inquiry as 'used to answer questions about the nature of phenomena with the purpose of describing and understanding the phenomena from the participant's point of view'.

Qualitative analysis was chosen for the following reasons:

- The research question being asked was contextual and exploratory rather than measurable or verifiable

- A natural setting was important to gain insights into the library layout and design, the library displays, how the books are shelved, the reading material on the shelves, where the computers are, what is the reading area like and what are the librarian/student interactions. (Creswell 2003).

- The topic was personally significant to the researcher who learnt from the participants' experiences (Leedy 1997).

\subsection{Interview method}

The interview was chosen as the main method of data collection for the following reasons:

- It is an appropriate means of gathering exhaustive data from school librarians who know a great deal about boys and reading within the timeframe available (Gorman and Clayton 2005).

- As many of the questions were opinion or broad open-ended questions dialogue between the researcher and participant was necessary for clarity and profundity (Gorman and Clayton 2005).

- The researcher was wary of focus groups being dominated by a strong individual and the geographical location of potential participants was unknown (Gorman and Clayton 2005). 


\subsection{Development of the questionnaire and interview questions}

\subsubsection{Questionnaire}

The questionnaire (Appendix D) was developed to precede the interview. The purpose of the questionnaire was to answer the yes/no and structured questions, answer the questions that required the participant to consult loan statistics and two of the questions were designed as 'ice breakers' and they were discussed in greater depth during the interview. Table 1 outlines which question addressed which research subquestion (stated in section 1.3.1).

Table 1: The questionnaire and corresponding research subquestion numbers

\begin{tabular}{ll}
\hline Questionnaire question number & Corres \\
& 1.3 .1 \\
1 & 4 \\
2 & 4 \\
3 & 3 \\
4 & 3 \\
5 & 1 \\
6 & 3 \\
7 & 4 \\
8 & 4
\end{tabular}

\subsubsection{Interview questions}

The interview (Appendix E) was semi-structured following the 'standardized open-ended interview' (Gorman and Clayton 2005, p. 127) format. The questions were prepared in advance and all participants were asked the same questions. The interview questions were grouped into four sections and each section addressed a research subquestion. They were grouped for the following reasons:

- To ensure each question asked related to a research subquestion.

- To streamline data analysis. 
- To break up the questions and make the interview seem less daunting for the participants.

Almost half of the questions originated directly from the literature citing comments from previous research on the issue and asking participants for their opinions.

The questionnaire was designed as the 'warm up'. After an initial 'settling' question the interview proceeded directly to in-depth questions. The questions were not so intensive during the latter part of the interview because if time was an issue they could be answered quickly.

\subsection{Delimitations and limitations}

\subsubsection{Delimitations}

The focus of this study is boys who are reluctant readers, that is boys who have the ability to read but choose not to read. Boys who have reading disabilities and have difficulty reading were not included in the study.

\subsubsection{Limitations}

The purposive sampling procedure has decreased the generality of the findings. The study findings are not necessarily applicable to all school libraries in New Zealand.

It is recognised that in asking for participants to volunteer for the study, potential participants with significant experiences and ideas may not have volunteered due to work loads or a reluctance to participate.

The sample is not representative of the normal distribution of New Zealand schools as discussed in section 4.1 . 
The four participants who were interviewed by telephone may have felt inhibited by this interview process.

\subsection{Human Ethics Committee}

On 27 January 2005 an application for approval from the Human Ethics Committee of Victoria University of Wellington was made for the study. On 4 March 2005 the researcher was notified that the research could not proceed as a proposed observation of students at the high school 'iibrary wnere the researcher worked required consent. from the parents of the students. The advice from the Human Ethics Committee was to forgo the observation and it was subsequently dropped. On 11 March 2005 a second application was submitted and final approval was granted on 18 March 2005.

\subsection{Pilot study}

Before commencing data collection the questionnaire and interview questions were trialled on seven librarians. The pilot study group were all known personally to the researcher and consisted of four school librarians, one English teacher with library responsibilities and two librarians from special libraries. The pilot study was also an opportunity for the researcher to experience interviewing and gauge the interview duration.

Feedback from the pilot study participants was welcomed and their comments were constructive. As a result of their comments both the questionnaire and interview questions were reworked and simplified. Data from the pilot study was not used in the final research results. 


\subsection{Sampling method}

For the study school librarians were purposefully selected who have actively and successfully encouraged reading among boys.

Kvale (1996) states that the sample size should include as many subjects as required until you are not finding out anything new. Kvale (1996) then goes on to say that in current interview studies, the number of interviews tend to be around $15 \pm 10^{\prime}$ (p. 102). Based on this information it was decided that the sample size for this study would be 12-15 subjects.

The National Library of New Zealand was approached to identify a list of school librarians who have successfully promoted reading from which a purposeful sample could be drawn. Two school advisors from National Library in Auckland could name only one school and advised posting a request on the New Zealand school librarians' listserv (schoollib). A request for participants (Appendix A) was posted on the list-serv and within a week 16 affirmative responses had been received. All 16 subjects were contacted as security in case of subjects withdrawing. As it happened two subjects withdrew from the study during its early stages.

The sample size of 14 was more than adequate for data gathering, however, one additional participant came into the study at a later stage as she was recommended by another participant and the information she gave was new information.

The final sample size was 15 participants.

While interviewing the participants it became clear that a snowball sampling method would also have worked in this study. Frequently participants suggested other school librarians who were knowledgeable about encouraging boys to read, however, due to the limited timeframe these leads with the exception of one participant, discussed above, could not be pursued. 


\subsection{Data collection}

Following the initial response from participants interview appointments were scheduled. Each participant was then sent a covering letter (Appendix B), a consent form (Appendix C) and a questionnaire (Appendix D). All the participants signed the consent form and completed the questionnaire which were then posted to the researcher in a pre-paid envelope provided.

The interviews took place during late March 2005 through to mid April 2005. The participants were sent the interview questions two days before their scheduled interview. One interview was postponed for two weeks by the participant, all other interviews took place at the scheduled date and time.

Eleven of the interviews were held at the schools where the librarians worked, six of these participants lived in Auckland where researcher is based and the other five were at other centres in the North Island which the researcher travelled to. The interviews generally lasted for 1 to $1 \frac{1}{2}$ hours although one went for $2 \frac{1}{2}$ hours as the researcher observed a 'Kid's Lit Quiz' while there. These interviews were recorded on tape, however, a school library is a not a quiet environment, there was background noise to contend with, frequent interruptions and during the interview the participant and researcher often shifted seeking a quieter location, therefore notes were also taken. During these interviews the researcher also observed the library and the librarian's interaction with students.

The remaining four participants lived in the South Island and these interviews were conducted by telephone. The facility to record these interviews was not available so notes were taken.

A small gift of note cards and envelopes was given to each participant at the end of the interview in appreciation of their time and knowledge. Participants in the South Island were sent their gifts. 


\subsection{Data analysis}

The interview tape and notes were transcribed as soon as possible after the interview. Each interview took approximately four hours to transcribe. The interviews were not transcribed verbatim but transcribed so that the essence and meaning of what was said still remained. For example during an interview a participant said 'The main way I promote reading is by talking to the boys. I tell a class in the library about the books I have been reading and say to them "Just read this book it's so cool"'. This was transcribed as 'Main way promote reading by talking - tell class about books been reading - "Just read this book it's so cool"'. Responses considered by the researcher to be significant or 'gems' were transcribed in full.

A copy of the transcribed interview was then sent to the participant for verification. The transcripts were sent via e-mail in two formats; word format and rich text format (rtf) The participant amended the transcript if necessary and then e-mailed it back to the researcher.

Prior to 'analysis proper' (Kvale 1996) the revised transcrips were then read through and clarified, 'making them amenable to analysis' (Kvale 1996, p. 190). Superfluous comments, repetitions and comments not directly relating to the study were eliminated. This was not done at the earlier transcribing stage as the researcher was not experienced enough to judge what was considered essential and non-essential and it was thought better to have irrelevant comments crossed out on the transcript than not there at all.

\subsubsection{Analysis proper}

Analysis proper was guided by the approach developed by Taylor and Bogdan (1998) which parallels the 'grounded theory' approach of Glaser and Strauss but is more concerned with gaining a deeper understanding of the issue being studied than building theory. 


\section{- Step 1: Look for emerging themes}

While interviewing, transcribing and reading the questionnaires 'hunches' and ideas evolved. Taylor and Bogdan (1998) advise to identify tentative themes but not to 'develop a stake in any particular idea until you have had a chance to hold it up to experience and check it out' (p. 143).

\section{- Step 2: Coding and sorting the data}

Microsoft Excel was used to code the questionnaire. The interview questions were coded using colour coding and Microsoft Excel.

Taylor and Bogdan (1998) state that the codes should fit the data and not vice versa.

Codes were refined and then the data was sorted into the coding categories. Negative data was also included.

During this process the researcher sought clarification from participants if comments were ambiguous or needed further explanation.

\section{- Step 4: Develop themes}

Taylor and Bogdan (1998) actually state, 'develop concepts and theoretical propositions' (p. 144), however, themes seem to have more significance in this study.

Data relevant to a theme were compared and some ideas became more tangible and other ideas were discarded. The themes identified were embedded in the practices of the participants and their vernacular was important to describing these practices. The theoretical framework enveloping the study also became more relevant at this stage.

\section{- Step 5: Read the literature}

Findings from other studies were compared with the current study which helped with the interpretation of the findings and added reality and substance to the themes that emerged from the current study. 


\subsection{Validating the findings}

To ensure the credibility of the findings and integrity of the research project the following validation methods were used (Creswell 2003 p. 196).

- Member-checking

The findings, discussion and conclusion sections of the narrative were sent to two participants, one from a primary school and one from a secondary school to confirm accuracy and completeness.

- Bias

Any bias on the part of the researcher is detailed in the role of the researcher (see section 1.5).

- Negative or discrepant Information

Findings that were contrary to the emergent themes were also reported and discussed in the findings.

- Peer debriefing

To add reality to the study, an English teacher with library responsibilities who was part of the pilot study reviewed the findings, discussion and conclusion sections. 


\section{Research Findings}

The research findings are presented below. The findings have been divided into sections. Each section is a subquestion (see section 1.3.1) of the main research question. Within each section the headings relate to each questionnaire and interview question. (Refer to Appendix D for the questionnaire and Appendix E for the interview questions.)

The findings below represent the views and experiences of 15 school librarians. The research has not been conducted anonymously. Some of the people interviewed had titles such as Library Centre Manager or Information Centre Manager, however, for fluency and anonymity they are referred to in this report as 'librarians'.

Throughout the remaining sections of this report the librarians interviewed will be referred to as 'participants'. However, contextually in some sentences, it makes more sense to use the term 'librarian'.

Direct quotations from the participants are included in the following sections and are enclosed with quotation marks. Quotations from participants which stand alone for emphasis are written in italics.

\subsection{Demographic profile of the participants and their schools}

The demographic profiles are included to provide substance and meaning to the findings. The demographic details of the schools have been gathered from the Ministry of Education web site 'Te Kete Ipurangi'.

Fourteen female school librarians and one male school librarian took part in the research.

Table 2 shows a break down of the school demographic details where the participants worked. 


\begin{tabular}{lllll}
\hline School Type & School Authority & Gender & $\begin{array}{l}\text { School } \\
\text { Decile } \\
\text { Level }\end{array}$ & Location \\
Private & Primary + intermediate & Single sex boys & 10 & Main centre \\
Private & Secondary & Single sex boys & 10 & Main centre \\
State & Intermediate & Co-ed & 8 & Town \\
State & Intermediate & Co-ed & 4 & Town \\
State & Primary & Co-ed & 10 & Main centre \\
State & Primary & Co-ed & 10 & Main centre \\
State & Primary & Co-ed & 8 & Main centre \\
State & Primary + intermediate & Co-ed & 10 & Main centre \\
State & Primary + intermediate & Co-ed & 4 & Main centre \\
State & Secondary & Co-ed & 3 & Small town \\
State & Secondary & Single sex boys & 3 & Main centre \\
State & Secondary & Single sex boys & 5 & Town \\
State & Secondary & Single sex boys & 6 & Main centre \\
State: & Primary + intermediate & Co-ed & 9 & Main centre \\
Integrated & & & & \\
State: & Secondary + intermediate & Single sex boys & 5 & Main centre \\
Integrated & & & &
\end{tabular}

The type of schools were fairly evenly distributed, $33 \%(n=5)$ were secondary schools, $27 \%(n=4)$ were primary and intermediate schools, $20 \%(n=3)$ were primary schools, $13 \%(n=2)$ intermediate schools and $7 \%(n=1)$ was a secondary and intermediate school The schools by type are shown in Figure 1 . 


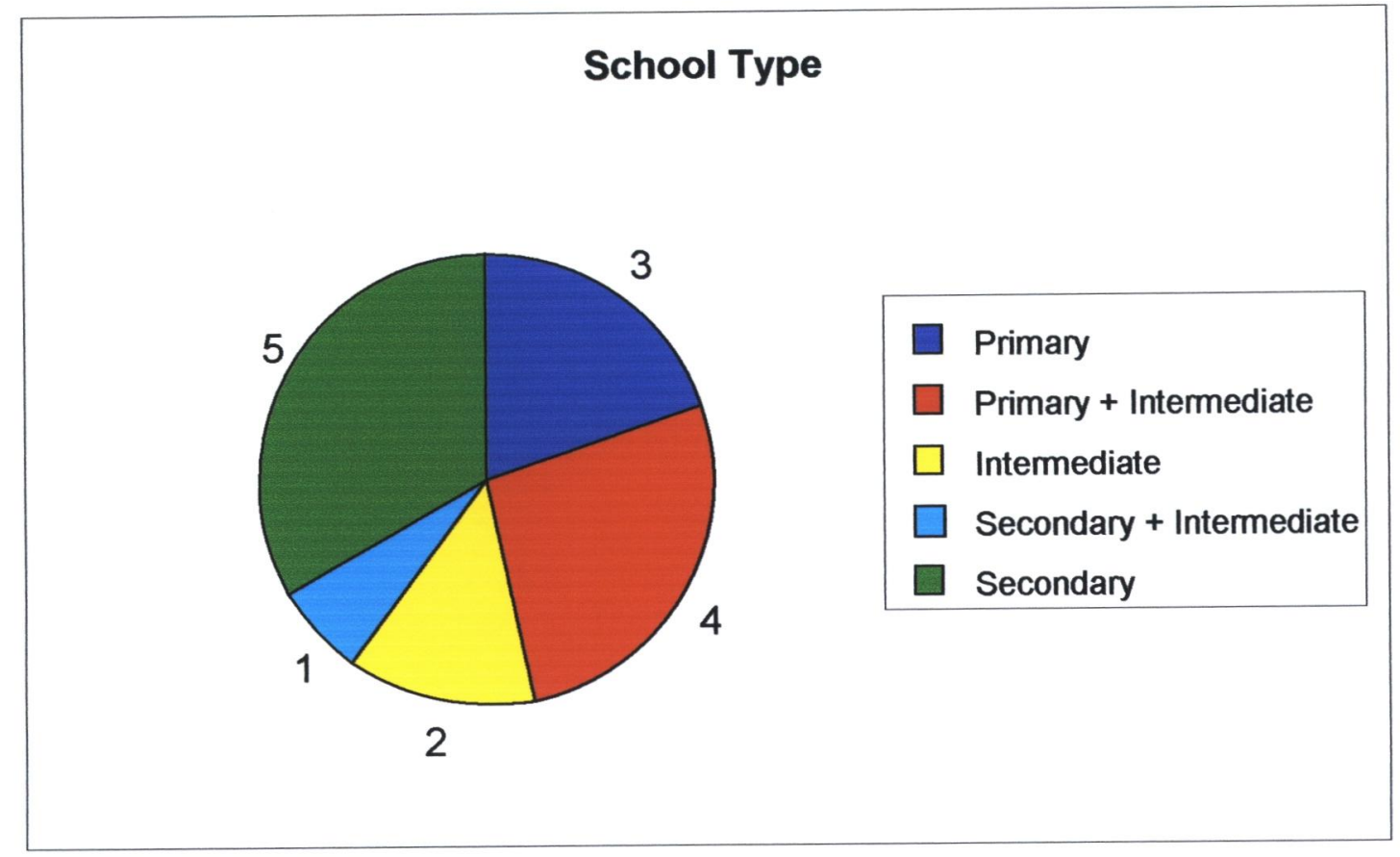

Figure 1: The proportion of schools by type

The decile levels of the school participating were skewed to the higher levels. According to the Ministry of Education, $10 \%$ of state schools in New Zealand have a decile level of 10. With the addition of two private schools at the top decile level, the distribution of decile levels is not a true representation of the population. $40 \%(\mathrm{n}=6)$ of the schools were single sex boys' schools which is also not representative of the population. However, the research sample was purposefully selected and, due to the topic being researched, a sample that closely resembled the population was not essential. 


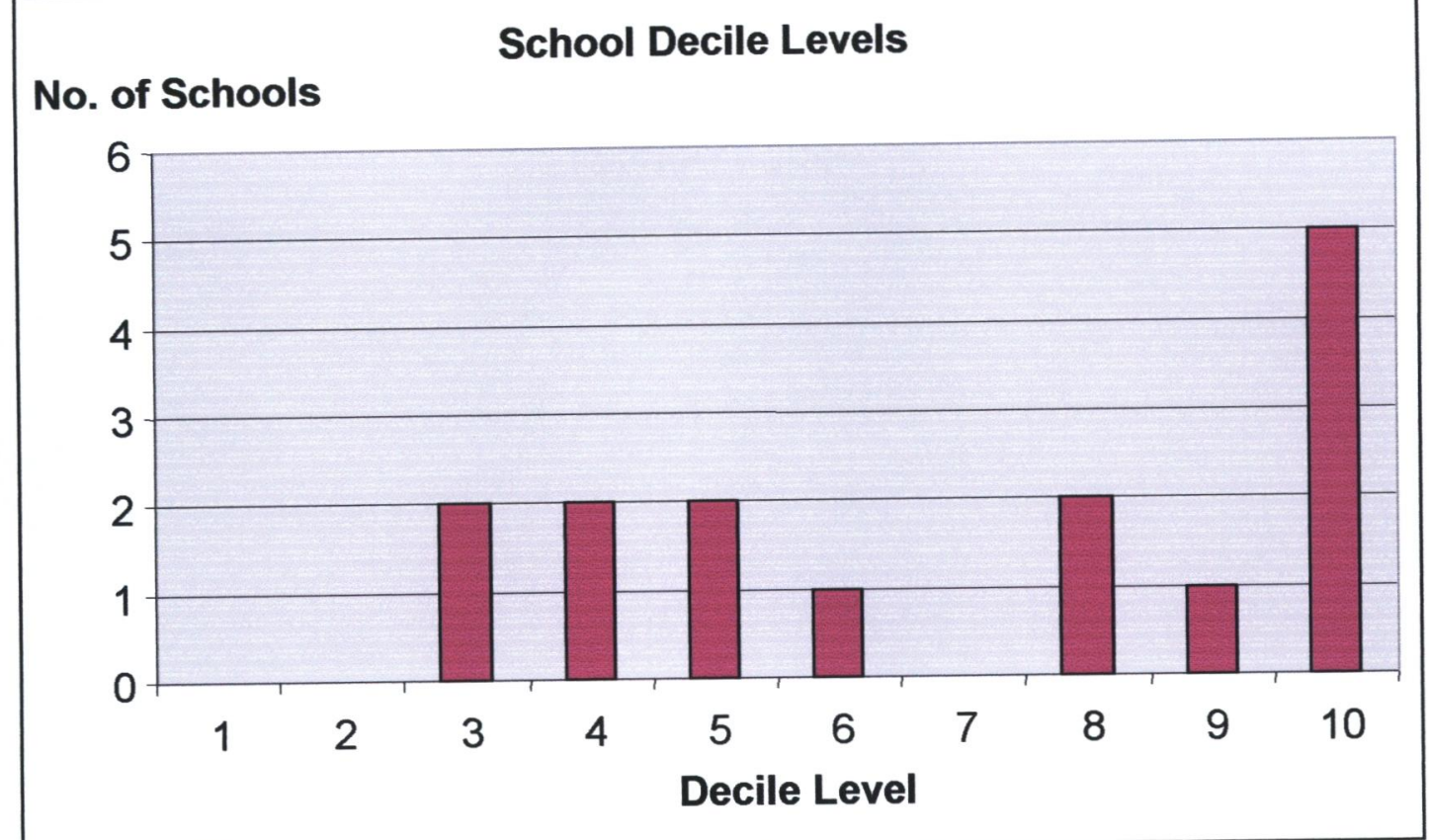

Figure 2: The decile levels of the participating schools 


\subsection{Strategies to encourage boys to read}

\subsubsection{Did you develop a strategy to encourage boys' reading or was it a gradual process that grew, or a way of thinking?}

$60 \%(n=9)$ of the participants reported that encouraging boys to read was a gradual process that evolved. It was a matter of observing the boys in the library, looking at ways to encourage them reading, introducing what they thought might help and continuing to add or modify as they went along. Four participants referred to it as a way of thinking. They were aware of the issue of boys and reading and, although it was not a conscious decision, they altered their own attitudes and views to boys and libraries.

Two participants developed specific strategies to target boys and reading. They observed that boys were not really interested in reading, decided on the most appropriate approach and went into action.

\subsubsection{What are the most important considerations when encouraging boys to read?}

This question combines both question 5 from the questionnaire and question 2 from the interview.

The considerations that emerged can be grouped into two categories:

- Whole-school literacy approach

- Literacy in the library

These categories can be broken down in to themes which are discussed in detail. 


\subsubsection{Whole school literacy approach}

Themes in the whole school literacy approach have been grouped as follows:

- $\quad$ Sustained Silent Reading (SSR)

- Role modelling reading

- Literacy award schemes

- Promoting reading

- Literacy week and author visits

Although the librarian is the driving force behind the majority of these approaches, the exception being SSR, they have been grouped as a whole-school approach because their success depends on the support of the principal and other staff.

\section{- Sustained Silent Reading (SSR)}

All the primary schools interviewed had a scheduled library time for each class to come in and choose books to read. SSR in intermediate and high schools means that students must read for a sustained period; how long depends on the individual school but it is usually between 20-40 minutes. How often during the week and what year levels take part in SSR, varies between schools. The reading material students are allowed to read, fiction, non-fiction, magazines will also vary between schools.

Of the six high schools participating in the research, three had an established SSR programme operating. One high school has replaced SSR with a 20 minute literacy activity, related to the subject being studied. Three times per week all students read subject-related books and magazines or do word puzzles or play word games. For example, following a Biology lesson, students read New Zealand Geographic magazines as a literacy activity. The literacy activities were introduced because teaching staff found SSR was too difficult to enforce. One participant from a school that did not have SSR stated that it needed staff support. Another school does not have SSR in theory, but quite a few English classes will come into the library and choose books to read for the rest of the lesson. One intermediate school also has SSR and one boys' preparatory boarding school has SSR for 20 minutes every evening as part of their prep. All the schools allow 
fiction and non-fiction reading during SSR and one school also allows selected lengthy magazine articles to be read.

As a participant from a boys-only secondary school described:

They are able to read non-fiction during SSR - not a picture history of World War II though, but 'Letters from the Coffin Trenches' would be OK.

Although SSR is the responsibility of the English Department, librarians have to supply the reading material and they use it as a time to encourage boys' reading by helping the boys find a book they would enjoy. This is not helped when students will turn up at the library two minutes before SSR time because they 'gotta get a book'. The advantages of SSR, one participant commented, is that it 'builds a reading habit' and another participant commented that it develops the ability to quickly read lots of text. It was also pointed out that the teachers must also read during SSR as a role model to the students.

\section{- Role modelling reading}

Role modelling reading is also discussed in section 4.3.2. Three schools use the 'book buddy reading system' where a senior student will pair up with a junior student and read to them which one participant said 'worked brilliantly'. Also boys of the same age can be book buddies who read and talk about a book with each other. They have to have read the book to discuss it with each other and one participant commented that it creates a supportive environment for reading.

In one high school library a 'favourite reads' programme is run during lunchtime. This happens four times a term during terms two, three and four. Teachers read to students from books they enjoyed reading when they were young and Year 13 boys say what they are reading which may include the New Zealand Road Code or Performance Car magazine. The participant is going to do 'favourite reads' with poetry this year. Included in role modelling reading, is reading aloud. As well as role modelling reading, one participant commented that what teachers are reading to the class will influence what they read. Another participant will find a good series and give the first book to the teacher to read to the class which then recommends the whole series to the class. 


\section{- Literacy award schemes}

One primary school participant has developed and runs a voluntary literacy award scheme. The scheme has different levels, bronze, cobalt, silver and gold and the reading requirements vary with each level. For example, to receive a silver medal a student must read at least one book from each of the eight genre to a total of 30 books. Each level has a list of books, compiled by the librarian, to choose from. The lists are a mixture of fiction and non-fiction. The librarian will discuss the books with the students to ensure they have read the books. When the students have read the required number of books for the reading level, they receive a medal at the school assembly and the student's school house receives 500 points. The emphasis of the scheme is reading for enjoyment and it has resulted in a greater enthusiasm for reading. It has 'generally lifted the profile of reading as a legitimate recreational activity'. However, it was commented that the success of the award scheme is dependent on the amount of teacher support.

Another participant ran an accelerated reading programme where boys read a book and then go to the computer and answer questions about it. She pointed out that there are pros and cons about the scheme as it has been reported that it does not encourage in-depth reading. Students are reading for quantity not quality. However, she observed that if the chosen books are well written they are receiving the quality as they read.

\section{- Promoting reading}

One school has 'books for boys' at assembly. The principal will promote books, given to him by the librarian, by reading an excerpt from the book or a review of the book. Another participant will talk with teachers about new books at staff meetings and the weekly school newsletter includes book reviews written by students; more boys than girls volunteer to write the reviews. A catch phrase at one school is 'have you got a book in your bag?' and at another school the boys all have book bags 'so reading is just part of school along with the sports bag and prep bag'. 


\section{- Literacy week and author visits}

Four schools, two primary and two high schools, run an annual literacy week, or book week. The purpose is to create a special focus on reading and books for that week through the school. Activities take place during the week that draw attention to books and the library. During the week, one school has the book bus from the local public library come to the school. Enrolment forms to join the library are given to students and they promote their books and other resources. At four schools, Scholastic Books come and display their books which students can purchase to take home and both participants report that it is popular and a good way to promote books.

Author visits are included during their literacy week and four other schools invite authors to visit the school during the year. All the schools belong to the New Zealand Book Council and author visits are subsidised by the Book Council. Authors are the heroes of the literary world. The visits are described as 'superb', the students enjoy the visits and one participant commented that it is important for the boys to see the person behind the books. The authors need to be credible for the students to relate to them. All the participants commented that the authors' books 'move from the shelves' after the visits. It must be noted that all the participants interviewed were supportive of New Zealand authors and their books. Authors who have visited the schools last year and are planned for this year include: Gavin Bishop, Glenn Colquhoun, Andrew Crowe, Ted Dawe, Brian Falkner, Jackie French, Kate de Goldi, David Hill, Paul Jennings, Lorraine Orman, Apirana Taylor and Albert Wendt.

Related to author visits are visits by personalities who can promote a book. One participant commented that the actress, Keisha Castle-Hughes visited the school and Whale Rider by Witi Ihimaera was suddenly popular as was Lord of the Rings by J.R.R. Tolkein when the screen co-writer brought his Oscar to show the children. As one participant pointed out 'capitalise on any book that has been turned into a movie' citing Holes by Louis Sachar as an example. 


\subsubsection{Literacy in the library}

Themes for literacy in the library have been grouped as follows:

- Book promotion in the library - silent promotion and booktalks

- How the librarian can help

- Book groups

- Literary quizzes

- Peer influence

- Book promotion in the library - silent promotion

Four schools colour photocopied new book covers and displayed them in the library as laminated posters on the walls or put them into plastic frames together with a copy of the blurb and displayed them on the library tables. In this case the titles were all fiction and the participant noted that the books do get borrowed as a result of the promotion. Notice boards were used in four libraries to display the current top ten reads and other book titles of interest. Six participants recommended plenty of high interest 'face out' books displayed as not only does it enliven the library, but it tends to be from where the boys will take the books.

Special displays of books were used by $60 \%(n=9)$ to varying degrees. Four schools, three primary and one intermediate used them to create the library 'wow' factor. The displays are theme related and visually stimulating, using posters and other props. For example, a book display on robots also had as many toy robots as the librarian could find. Changing regularly, they are designed to keep the library interesting as well as promoting books. One co-ed primary school also has a 'books for boys' display area. It is mainly intended for the first chapter book readers and gives them a place to go and look for a book without feeling intimidated. New book displays were mentioned and two schools displayed books that were recommended by other students or teachers. Whether students could take books from the displays varied. 


\section{- Book promotion in the library - booktalks}

Booktalks were used in six primary and intermediate schools and one secondary school during class visits to the library. Participants would gather up the new titles they wanted to promote and ask the teacher if they could spend a few minutes talking about the books 'selling' them to the students. As one participant noted, it is far more convincing if you have read the books first and are able to tell them about it in your own words. If the book is by a popular author say 'here is another one by ...' Participants read an excerpt from the book and report that children will queue up for the books.

As a participant from a boys-only primary and intermediate school explained:

Show some of the books and read aloud an excerpt from them - stop at a good exciting part.

\section{- How the librarian can help}

All the participants stressed the importance of knowing the collection and knowing the students and this is discussed further in section 4.4.4.

Three participants commented that boys need time to select a book. Allowing five minutes to find a suitable book is not enough. All the participants said it was important that the librarian be there to help them find a book and to be aware that boys read a wide range of fiction and non-fiction. Go through asking questions such as what their interests are, what was the last book they read, did they enjoy it, why, why not, what are your friends reading, what authors do you like, what type of stories do you enjoy? As one participant pointed out, the librarian can start asking these questions and encourage the boys to think about these questions for themselves. Encouraging boys to evaluate a book by reading the blurb at the back, reading the first couple of pages and asking does it 'grab you' was also mentioned. 'Try this and tell me what you think' is another tactic to encourage boys to read a book. $47 \%(n=7)$ of participants commented that boys need to be aware that if they are not enjoying a book they do not have to persevere and finish it; they can 'stop reading it and we will look for another'. One participant stated that as well 
as helping the boys who are looking for books it was also necessary to 'pin down' the boys circling around avoiding reading.

The 'home run' book was mentioned by six participants. The 'home run' book is a term used to describe the first book a child enjoyed reading and encourages them to read more books.

All the participants listened to suggested titles from the students which relates to buying what the boys want to read.

As a participant from a co-ed primary and intermediate school remarked:

Without the right reading material it would be hopeless. You have to buy what they want to read even if you don't like it.

Also a participant from a boys-only secondary school:

There is no point buying a book if the students will not read it even if teachers think they are worthy books. You want the books to move from the shelves.

One participant has formally surveyed the students asking what they wanted to read, mind mapped the result and put them into lists. Other participants ask students to help when selecting books for the library. However, it should be noted that all the participants kept within the bounds of what is suitable material for a school library.

\section{- Quizzes}

Three school took part in the 'Kids' Lit Quiz'. The quiz has been devised and run by Wayne Mills of the University of Auckland as a way of encouraging reading at the 10-13 years age group. Teams of 4 students compete in the quizzes and the winning team from the school competes in the New Zealand 'Kids' Lit Quiz'. The quiz appeals to the boys' competitive spirit and they are reported to be 'very enthusiastic' about it. At one co-ed intermediate school there are more boys than girls entering the competition. 
One participant from a boys-only high school library runs quizzes about specific books for example Tomorrow When the War Began by John Marsden and Lord of the Rings by J.R.R. Tolkein have all been subjects.

Quizzes that are not strictly tied to knowledge of books are discussed in section 4.5.3.

\section{- Book groups}

Three participants ran book groups. One participant ran a book group for boys who were selected by their teachers because they were having difficulty finding a book they liked to read. The librarian spread a selection of books out on a table and discussed them with the boys. The participant reported that at the time she thought it was not working but when it stopped the boys came up asking for it to continue as they enjoyed it so much and all the boys are now enthusiastic readers. Another participant runs two book clubs in the library. One is run on a Friday lunch time. The book club group can eat their lunch in the library and the library is closed to other students. The librarian organizes literacy games and promotes books, discussing them and reading excerpts. She reports that it has 'hooked in' the boys. Another book club is run on Friday afternoons for the more serious readers where they can sit and read quietly and they get first choice of the new books.

\section{- Peer influence}

Although this is discussed in section 4.3.5 it is also included in this section as one participant has successfully used it as a specific strategy to encourage boys to read. This participant believes that boys, high school boys in this case, respond to other boys in their peer group rather than adults. Boys will discuss books with each other in a joking, jovial atmosphere. The librarian targets boys who are 'cool', respected by other boys and if a co-ed school a 'presence with the girls' is also an advantage. She will find these boys a 'home run' book and use them as a marketing tool to promote the books to other boys. The participant cited an example. One boy played sport internationally for New Zealand; he was 'cool', admired by his peers and needed books to read while he travelled. The librarian talked to him about his interests and what he liked reading and gave him a book 
bag. When the boy returned he enthusiastically recommended the books he had enjoyed reading to his friends.

\subsubsection{What have been the results?}

Nearly half the participants, $47 \%(n=7)$ reported that, generally speaking, boys have a greater enthusiasm for reading as a result of the initiatives discussed above. Many boys, not all, are recommending books to friends, reading widely and are generally happy reading. One participant observed that some boys who were known as trouble-makers are now keen readers and are coming back to the librarian saying that they want another book just like it.

As a participant from a boys-only intermediate and secondary school observed:

I know there are boys going out of the school who no longer see books as enemies.

$27 \%(n=4)$ participants commented that the boys are happy in the library. One participant added that the students feel as if they own the library. The sole male participant reported that use of the library has grown exponentially especially amongst the boys.

A positive result, one participant reported, are parents coming up to her and thanking her for developing a love of reading in their sons. Two participants talked of increased loan statistics and two participants reported an improvement in student reading levels.

Participants were asked if the focus on encouraging boys to read has been successful for all boys in the school regardless of their reading ability, ethnic and socio-economic background.

Only five participants were asked, or responded to this question. One participant agreed that every boy in the school benefited, the remaining four said 'realistically no', but it has certainly been successful for many of them. 
Participants from co-educational schools were also asked what effect encouraging boys to read has had on girls' reading.

Participants who responded to this question replied that they still looked after the reading requirements of girls and it was pointed out that the effect has been positive as girls will also benefit from any school focus on reading.

\title{
4.2.4 Are there plans to develop it further, i.e. where to from here?
}

\begin{abstract}
About half, $47 \%(n=7)$ of the participants reported that they had no plans for change and another two participants plan to keep the status quo but are always looking out for new trends and ideas. The remaining six participants will implement or would like to see some further developments. Examples include, one primary school participant investigating purchasing magazines for the school library that will appeal to boys such as the Horrible Histories magazines and another participant will introduce more Quick Facts books that are popular with boys. One participant would like to see SSR go all the way through the school and reports it is getting there on an ad hoc basis. Another participant who runs the literacy award scheme has introduced new book lists and intends to monitor the new lists.
\end{abstract}

\subsubsection{Do you think this would be successful in other schools?}

All participants agreed that the strategies they were using would be successful in other schools except one participant who thought that schools with lower literacy levels would require a more direct approach as this participant's approach had been very 'low key'.

'It is no magic formula' said one participant 'as long as there are males to role model reading'. Other participants felt that as long as the librarian knew the children and had an excellent knowledge of children's books it would work anywhere. It was also pointed 
out that a positive attitude was required and librarian's had to get away from a 'don't touch the books approach' and adopt a non-confrontational stance.

It was agreed that literacy award schemes and SSR would work in any school as long as there was 'someone to drive it'.

\subsubsection{What other organisations did you seek guidance and support from?}

A wide variety of sources were referred to by the participants; journals, organisations, web sites, books published on the subject and other people. The tables below detail the sources.

Four participants each mentioned a book as being helpful. The titles and authors are:

- Radical Reflections by Mem Fox

- The Reading Bug ... and How to Help Your Child Catch it by Paul Jennings

- Keeping Them Reading by Mary Leonhardt

- Boys and books: Building a Culture of Reading Around Our Boys by James Moloney

Table 3: Joumals referred to by the participants Journal

Around the Bookshops $\%$ of participants who cited journal

Literature Base

$7 \%(n=1)$

Magpies

$20 \%(n=3)$

Newspapers

$53 \%(n=8)$

SET

$20 \%(n=3)$

$7 \%(n=1)$ 
Table 4: Organisations referred to by the participants

Organisation

$\%$ of participants who cited

organisation

Children's Literature Foundation of New Zealand

$33 \%(n=5)$

National Library

$20 \%(n=3)$

National Library Area Meetings

$33 \%(n=5)$

Reading Association

$13 \%(n=2)$

SLANZA

$33 \%(n=5)$

Table 5: Persons referred to by the participants

Person

$\%$ of participants who cited person

Book groups

$20 \%(n=3)$

Local children's booksellers

$27 \%(n=4)$

Other librarians

$20 \%(n=3)$

Teachers

$7 \%(n=1)$

Visiting Speakers

$13 \%(n=2)$

Table 6: Web sites referred to by the participants

\begin{tabular}{lll}
\hline Web Site & Web address & $\begin{array}{l}\% \text { of participants } \\
\text { who referred to } \\
\text { web site }\end{array}$ \\
$\begin{array}{lll}\text { Achuka } & \text { www.achuka.co.uk } & 13 \%(n=2) \\
\text { Amazon - Explore Similar } & \text { www.amazon.com } & 20 \%(n=3) \\
\text { Items } & & \\
\begin{array}{l}\text { Christchurch Public } \\
\text { Library Pulse web site }\end{array} & \text { pulse.christchurch.prg.nz/goodreads/ } & 7 \%(n=1) \\
\text { Cool Reads } & \text { www.cool-reads.co.uk/ } & \\
\text { Guys Read (Jon Scieska) } & \text { www.guysread.com } & 13 \%(n=2) \\
\text { Nancy Keane } & \text { www.nancykeane.com/ } & 13 \%(n=2) \\
\text { NZ Book Council } & \text { www.bookcouncil.org.nz } & 7 \%(n=1) \\
\text { Story-go-round } & \text { homepages.ihug.co.nz/ l.orman/index.htm } & 13 \%(n=2) \\
\text { Trinity College - Perth } & \text { www.trinity.wa.edu.au/plduffyrc/teaching/boyread } & 7 \%(n=1) \\
\text { Wheeler's Books } & \text {.htm } & 7 \%(n=1)\end{array}$ \\
\hline
\end{tabular}


The percentages quoted do not give any indication of the enthusiasm participants gave to specific organisations.

The most significant book was Keeping them Reading by Mary Leonhardt. Magpies was the most popular journal and was considered 'excellent' by the participants who consult it and it has good lists of books for encouraging boys to read. The Literature Base was also considered useful. The Children's Literature Foundation was highly praised by the participants who belong to it and National Library provided a 'valuable' service in the smaller centres. Book groups where a 'group of like minded individuals meet to discuss children's and young adult books' were considered a very good resource. Local specialist children's book sellers were 'excellent' as they gave valuable support and advice to school librarians who often work in isolation. One participant also mentioned Wayne Mills from the University of Auckland and Rob Southin from Scholastic Books as having 'tremendous knowledge' on the subject. Lorrain Orman's Story-Go-Round web site was considered good especially for fantasy. Wheeler's web site was good for new books and both Achuka and the Nancy Keane web sites were highly recommended. 


\subsection{Influences on boys' attitudes and behaviour in the library}

\subsubsection{What methods are used to help students find a book?}

It is recognized by the researcher that all the schools surveyed had OPAC terminals available for students to search the catalogue. However, the purpose behind this question was to search deeper than the OPAC and discover what other tools are employed to help students locate books in the library. Also all the participants are available to help students locate books even if it means scheduling parent help for class visits to the library

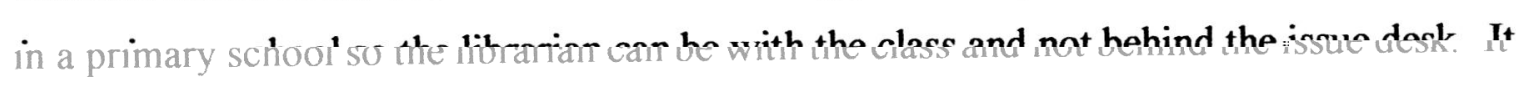
is important as one participant highlighted to 'keep putting yourself out there'?

The following table summarises the methods used to help students locate a book

Table 7: Methods used to assist students locating a book

$\begin{array}{ll}\text { Location method } & \% \text { of participants who used the method } \\ \text { Specific collections together } & 87 \%(n=13) \\ \text { Reading lists } & 53 \%(n=8) \\ \text { Spine labels } & 40 \%(n=6) \\ \text { Shelf dividers } & 33 \%(n=5) \\ \text { Other methods } & 33 \%(n=5)\end{array}$

Most of the schools do group a specific type of book together, label the collection and put the books in a bin or on shelves that students can go directly to without searching the shelves. In some primary schools the fiction collection was divided into junior or senior levels. In high schools, 'easy reads' (although they were never labelled as such) were grouped together and labelled 'fast zone readers', 'quick reads' or 'short and snappy' They consisted of both fiction and non-fiction, high interest reads with illustrations, less than 100 pages and at differing reading levels. The collection was aimed mainly at boys who were not yet confident enough to read a novel but could still go in to the library and find without great difficulty and embarrassment something of interest to read. Along with a separate 'quick reads' bin, one intermediate school has next to it a 'Librarian's 
choice' bin which has titles selected by the librarian and will stretch the reader more than quick reads.

Other special collections in high schools were graphic novels and sophisticated picture books. One high school library has 'easy reads' and graphic novels together. It is aimed at boys and less confident readers could go to this area without feeling embarrassed. In primary schools one school has puzzle books, graphic novels and the 'Horrible History' series all in bins next to each other creating a boys' corner. While one primary school has a special 'books for boys' display area no school had a special boys' section in the library.

One primary school has this year created a special junior non-fiction collection near the picture books which is proving successful as these books tended to get lost in the general non-fiction collection. With colourful Sybasign shelf dividers, junior children can easily find non-fiction titles of interest without having to leave their 'area' of the library. As one participant noted 'the idea is to get them in and then make it easy for them to find books in the library'.

The participants who had created reading lists for students were evenly spread between high schools and primary schools. The schools using reading lists in the high schools were boys-only schools and lists included non-fiction and fiction. The non-fiction titles were not 'how to' books or more illustration than text titles. One high school reading list included journal articles taken from the Listener or New Scientist and would take a boy about 20 minutes to read as well as poetry and graphic novels. One participant stated that the reading lists are working well as 'they encourage the boys to read more widely'.

Reading lists in primary and intermediate schools can be part of a literacy award scheme or folders or brochures in the library or lists on the wall recommending books. One primary school had genre folders (fantasy, adventure, mystery, animal and history) with a page for each title featuring a scanned book cover and a bit about the book. Another school had brochures with the 'if you enjoyed reading this try this' theme. For example, 
if you enjoyed reading Horrible Histories try reading Murderous Maths. An intermediate school had book lists on the wall for boys and girls with the heading 'Can't find a good book? Try these great reads'.

Spine labelling consisted of genre labels and colour coded labels. Two high schools used genre labels and had a key to the genre labels on the wall. One participant commented that it was useful for the students and for herself when students came asking for a book of a specific genre when she was busy and could tell them 'war stories - look for a book with a tank on the spine'. One participant inherited a collection with genre labels and found it inconsistent and confusing when there was more than one genre label on the spine and feels that genre labels discourage serendipity.

Colour coded spine labels were used in primary schools to indicate books for a certain reading level. For example one school colour coded emergent readers' first chapter books as 'it is a big step up from picture books to chapter books and some may get lost along the way'.

Another school had their Dewey classification colour coded as it helped boys locate an area they were specifically interested in for example sporting books.

Shelf dividers for non-fiction divide Dewey into topics. Two primary schools used Dewey Sybasigns (see Figure 3) which can be specific. For example, one school's shelf dividers read: 597 Reptiles and fish; 598 Birds; 599 Mammals; 600 Technology; 609 Inventions; 612 Human body; 621 Machines; 629.4 Spacecraft. Another primary school had bespoke shelf dividers in vivid black writing on a red background. The shelf dividers indicate areas of high interest for example scooters and skateboarding. 


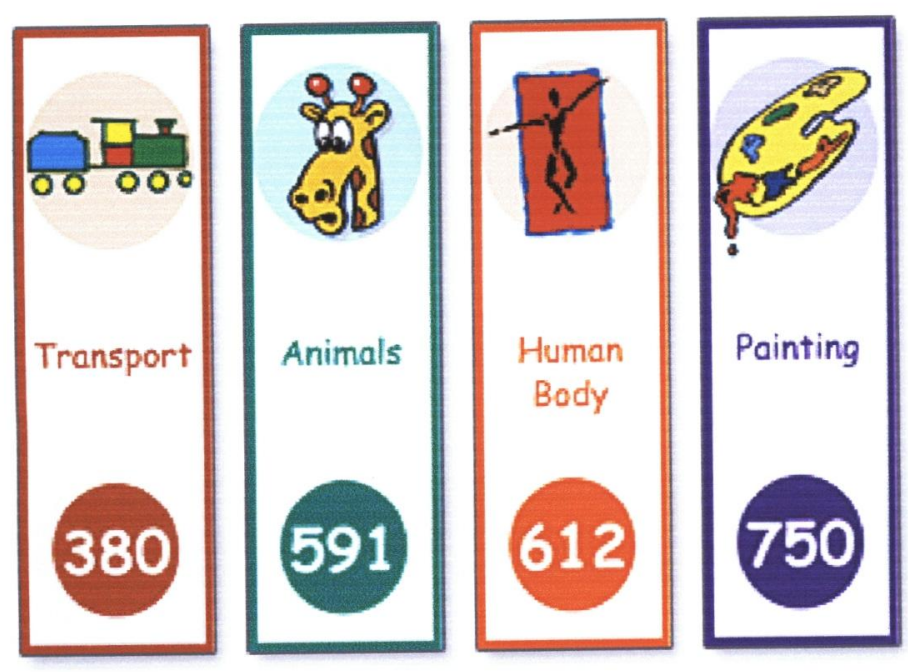

Figure 3: A sample of Sybasigns

Image reproduced with permission from Sybasigns (http://www.sybasigns.com.au)

Other methods include displays. As in a book shop, one school displays the popular titles face out on the shelves so students can find them quickly. At the beginning of each school year one participant collects all the 'popular reads that are never on the shelves' and creates a special display called 'cool reads' for junior students at a high school. The new juniors can then go straight to this display and select a title instead of being overwhelmed by the fiction section.

One participant includes on the catalogue record the scanned cover of each book title and another participant indicates where the book can be found in the library during a booktalk. To encourage a degree of self help some schools create folders with nonfiction key words and subject headings with the corresponding Dewey number. As one participant observes 'it is a generation that wants it spoon fed to them, they don't want to read through chunks of stuff they want pictures and key words. It's a kind of laziness really they have no trouble finding books on stuff that they want like sex, drugs and guns'. 


\subsubsection{Many boys perceive reading, especially if their fathers do not read books, to be a feminine activity and therefore not something males do. In a library that is usually staffed by women how do you overcome this negative perception?}

All participants were aware of this problem and there were a range of responses. $47 \%$ $(n=7)$ talked about male role modelling while one respondent took the 'get over it' approach. As the one male participant acknowledged, it is not an issue at their school and schools that had more male teachers than female also said it was not such a big deal. Role modelling reading included providing the male teachers, especially the 'cool ones', in the school with books and telling them to read them, be seen reading them and talk to the students about the books. Role modelling also took the form of asking male teachers or fathers to come and read in the library at lunchtimes. Two participants have also used 'hero boys' as role models, where older boys read to younger boys in the school or at a neighbouring school and it works well. Tutors in boarding school are mostly young men in their gap year from Britain and they enjoy reading and role model it successfully. One participant will tell boys that her son enjoyed this book as their perception is that a middle aged woman cannot like the same books as they do.

As a participant from a boys-only secondary school commented:

It's like saying you enjoy the same music as they do-to them, the music cannot be loud and horrible enough.

Trying not to feminise the library was another theme that emerged with $40 \%(n=6)$ participants discussing it. One school has a boys' committee for book selection. Another participant has posters with 'boy appeal' on the library walls such as cars and the American Library Association posters showing sports stars and musicians reading books. One participant will actively recruit more male librarians if necessary and in one boysonly high school the librarian at lunch times and intervals will try and stay in her office as student librarians are there to help and it becomes a male environment. 
Other approaches were that the boys should see you as a real person active in the school outside the library or that the librarian's enthusiasm and interest in reading would outweigh any negative perceptions.

One participant responded that boys at her school are aware that 'boys don't read' however, they consider that, because they don't read a novel they are not readers when they do read magazines and non-fiction.

As a participant from a co-ed primary school observed:

Most school librarians are women and read novels therefore they consider boys are only reading if they read fiction novels.

Reading the newspaper, reading magazines and reading the Guinness Book of Records is still reading, boys read a range of materials. All the participants listened to boys' suggestions and presented a choice of reading material which can overcome the 'boys don't read' perception.

As a participant from a co-ed primary school explained:

Give them choices - with guidance, don't say they have to read that or have to read fiction - it can become a downward spiral - but find the right reading matter so they want to read.

One aspect of this question that was difficult to answer was the issue of fathers who do not role model reading and how to address it. Librarians at lower decile schools particularly acknowledged the problem of reading having little importance in the home. However, one participant from a high decile primary school also commented that when she encourages parents especially fathers to read to their sons many fathers respond 'we don't read'.

Last year one participant at a decile five boys-only high school organised a 'dads'n'lads' evening as the literacy side of the 'dads'n'lads' programme at the school. The evening was aimed at Year nine boys who came with their fathers, supper was provided as an incentive and a gold coin koha was suggested. Wayne Mills spoke and was 'amazing' he recommended books and gave out book lists. David Hill who had been at the school for 
an author visit also spoke as a guest spot and was 'excellent'. The library was full and the evening was so successful it will be repeated this year.

Another participant has a power point display on the school web site which is aimed at parents and is about encouraging boys to read. This participant also has a desk stacked with books in the hall during parent-teacher interviews and asks parents if they might like to donate a book to the school library.

To get parents more involved in reading, one participant has book fairs in the evening so parents can come too. Also the library is kept open during the parent - teacher interviews. Parents are invited in to look around the library and for some it is their first experience of what a school library is like.

\subsubsection{Generally speaking boys would prefer to be playing sports, being with friends, watching TV, or on the computer rather than reading. a) How do you overcome this?}

Two participants did not see this as an issue in their schools and one commented that although the school had a strong sporting code, sport and reading complement each other.

All the participants felt that reading should not compete with other activities but be offered as an acceptable alternative creating a win win situation.

As a participant from co-ed primary and intermediate school remarked:

I don't think that they necessarily see things as either or. They read AND play with their friends AND play sports .... In other words, one activity (reading) doesn't need to preclude another.

$33 \%(n=5)$ of participants felt the appeal of the library should be extended. Making the library a friendly environment for boys included the use of computers, games, an extensive selection of magazines and books on sport and their interests. One participant has the school sports teams and sports results pinned up in the library which draws the boys in and makes it acceptable for them to be there and the librarian can then extend 
some influence on them. This is what one participant termed the 'sucky in things'. To entice boys into the library web sites of interest that relate to books are catalogued. For example, as well as having the Deltora Quest books by Emily Rodda on the catalogue, web sites relating to Deltora Quest on are on the OPAC. One participant noted that book lists have made a big difference to boys seeing reading as an acceptable alternative to other activities.

\subsection{4 b) How do you overcome the image of the 'library geek'?}

Participants who worked in primary schools commented that it was really not a problem at that age. High school librarians commented that it does not stop boys coming to the library.

As a participant from boys-only secondary school commented:

The library is a cool place to be for the geeks and nerds but the jocks come in as well. They come because a) it is open, b) it is warm, c) it has computers and d) it has books.

Two participants commented that the library is seen as a cool place to be because the seniors use the library as a study room and if they are there it must be ok. One participant observed that the more students you get into the library the more the image of the 'library geek' dissipates and the loners have to socialise as well. Another participant noted that as the library has become so popular the 'geeks' have been driven away.

\subsubsection{What other influences do you see as important on boys and reading?}

The majority of participants, $80 \%(n=12)$ stressed the important influence of the peer group on reading. All $80 \%$ reported that boys discuss and recommend books to each other.

As a participant from a co-ed primary and intermediate school observed:

Boys like a book they can share with friends - girls like to read a book through on their own - boys like to copy drawings. They take more out of a book than girls do. 
Participants encourage boys to recommend books to each other and three participants, all at high schools mentioned that they will 'rave' about a book to one boy and he will in turn talk about it to his friends. Four participants encouraged students to write book reviews that can that are published in the school newsletter or on the Information Centre web site and one participant will reward students who write book reviews. As one participant said a one word review such as 'cool' or 'crap' is sufficient.

A simple recommendation form (see Figure 4) is used by one primary school; there is a special display shelf for these books with the recommendation slips attached.

One participant also pointed out that if the peer group are non-readers then the pressure to conform as a non-reader is very strong.

\section{This Book Is Good}

\section{Recommend It}

\section{student name}

Figure 4: A book recommendation slip

$47 \%(n=7)$ of participants also reported that the support and encouragement boys receive from the principal, teachers and a general school wide focus on literacy is also an important influence. Male staff role modelling reading and the principal promoting books at assembly reinforces and supports the work of the librarian. One participant commented that the school focus for 2005 is boys and reading. Related to this, one participant mentioned a well stocked and welcoming library environment is another influence. One participant questioned the role of the media and that they do not always promote reading as being important. 


\subsubsection{It has been observed that boys require more guidance than girls selecting a book to read and during set reading times in the library they are more likely to come without a book or would re-read a book as it is a safer option than selecting a new book. From observation in your library what is your opinion?}

$60 \%(n=9)$ agreed with this statement, $20 \%(n=3)$ said possibly and $20 \%(n=3)$ said this was not true. The participants who said it was not true were from primary schools and said that both boys and girls equally required help.

Five participants who agreed with the statement said that boys will go back to the same book explaining that it was 'a security thing' or because they are 'more intimidated by the [library] system'. As one participant explained 'boys will re-read a book till they are confident and have knowledge of the library to select another book'.

Four participants who agreed with the statement commented that boys are more reluctant to ask for help than girls and 'need more input' as they are 'not as good as girls at expressing what they like or read'. Highlighting the situation one participant commented 'girls will communicate more what they want, boys hang around the shelves'.

All the participants agreed that series are really useful for boys. Once they are 'hooked' on a series they will read it through and then ask for another 'just the same'. It was pointed out that it is crucial when boys have finished one series that the librarian steps in and guides them to another series they will enjoy. 


\subsection{Choosing books for boys}

\subsubsection{From the questionnaire you have listed the following as important considerations when choosing fiction for boys. Could you explain them in more detail and why they are considered important?}

This question also incorporates question 3 from the questionnaire. All participants collected fiction specifically for boys and the important considerations that emerged are;

- book packaging

- genre

- content of the book

- authors

- series

- currency of the collection.

As a participant from a boys-only secondary and intermediate school described:

Boys choose books first by the cover, second by the blurb on the back of the book and third by what it looks like inside.

The book packaging includes the cover; the layout and the illustrations. Every participant stressed the importance of the cover when selecting books for boys as they do 'judge a book by its cover'.

What constitutes an appealing cover? Table 8 details the findings. 
Colour

Cover illustration

Boy on cover

Girl on cover

Animals on the cover

Also
Bright bold colours at primary school level such as the Kiwi Bites and the Aussie

Bites series.

Strong, clear use of colour at secondary school level for example Thunder Road by Ted Dawe.

Realistic illustrations that reflect what the book is about. Simple and clear graphics for example any cover from the Alpha Force series by Chris Ryan See Figure 6.

'The boy must look older than the age group who will read the book and preferably he will be doing something exciting'. For example Dacked by Andrew Daddo and Terry Denton. See Figure 5.

Never have girls on the cover was the general consensus though one participant said the cover must not be dominated by a female figure. One participant from a primary school commented that one boy said he did not mind girls on the cover 'as long as it was a good story'.

Sharks, snakes, dragons, scorpions all emotive images suggesting danger. For example Skeleton Key by Anthony Horowitz.

Embossed surface, holographs and weapons such as guns or daggers, for example Grass for his Pillow from The Tales of Otori series by Lian Hearn.
Vague, bland and insipid colours that look a blur from a distance such as The Real Thing by Brian Falkner. See Figure 8.

Abstract art or messy, oldfashioned illustrations for example See Ya Simon by David Hill. Nothing cute, pretty or babyish.

The boy looks younger than the intended reading age for example Henry and the Flea by Brian Falkner. If he looks too young, particularly in quick reads it will be perceived as a babyish book

If there is a girl on the cover the librarian will have to 'sell it' for example Remembrance by Theresa Breslin. See Figure 7

No horses or cute animals, for example Max the Mucky Puppy by Jenny Dale.

A cover that does not reflect what the book is about for example Malcolm and Juliet by Bernard Beckett

Seven participants said that if the cover was bad they had to work hard to 'sell it', telling the student that the cover was 'rubbish' but to try the book. Two participants admitted turning down books because of the covers and four participants agreed that the book had to be very, very good for them to buy it if it had a bad cover. It was generally agreed that book covers are getting better although four participants agreed that New Zealand book covers were often found wanting. One participant has purchased new publications of books that have more appealing covers than the older editions as the boys will read them. 


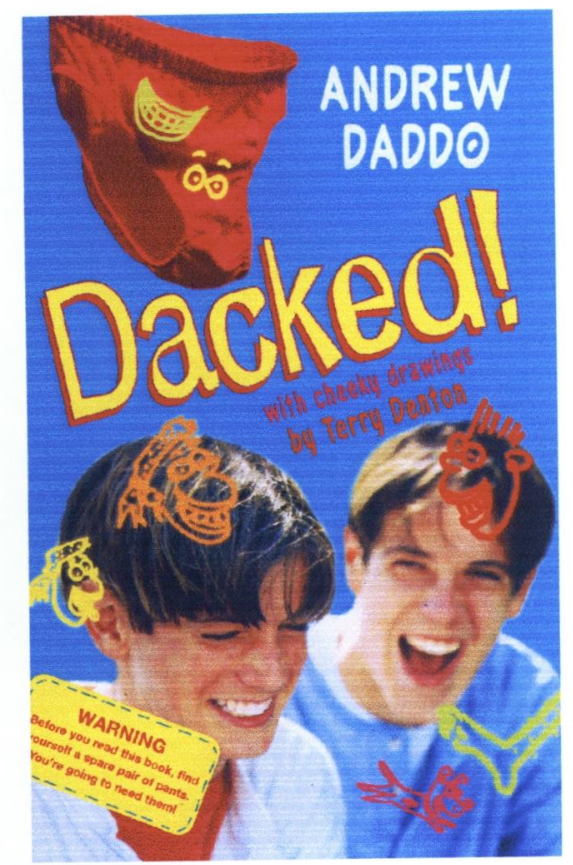

Figure 5: Dacked!

A bright, colourful cover hinting at 'toilet humour' and fun. The boys look older than the intended reading age of primary school boys.

Cover from Dacked! by Andrew Daddo and Terry Denton, 2003, reproduced with permission from the publisher, Hachette Children's Books, Australia.

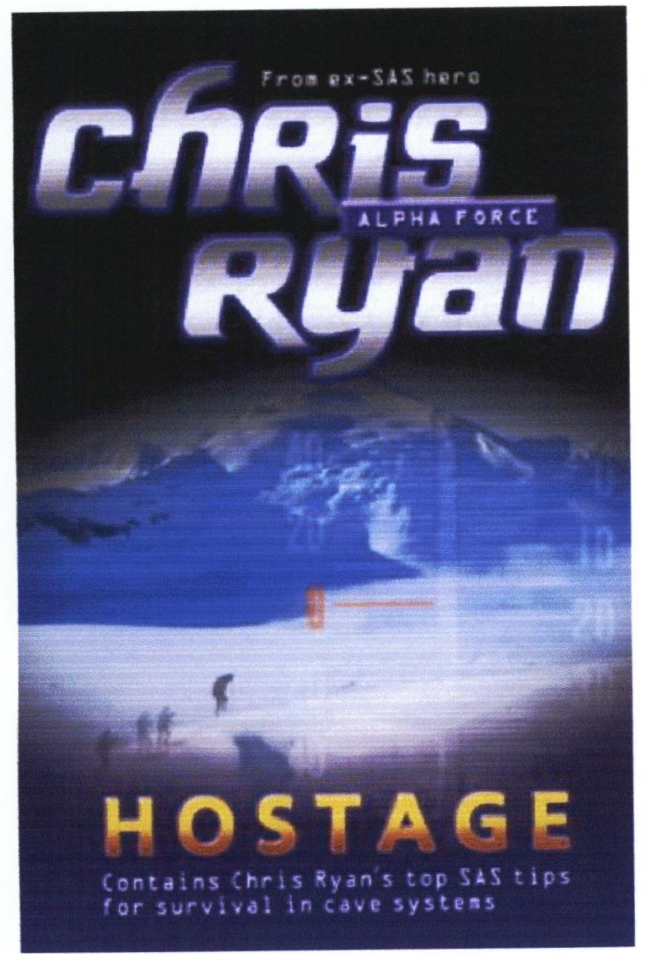

Figure 6: Alpha Force: Hostage

A cover that immediately conveys what the book is about and suggests suspense and action. Cover from Alpha Force: Hostage by Chris Ryan, 2003, reproduced with permission of the publisher, Red Fox Books, London. 


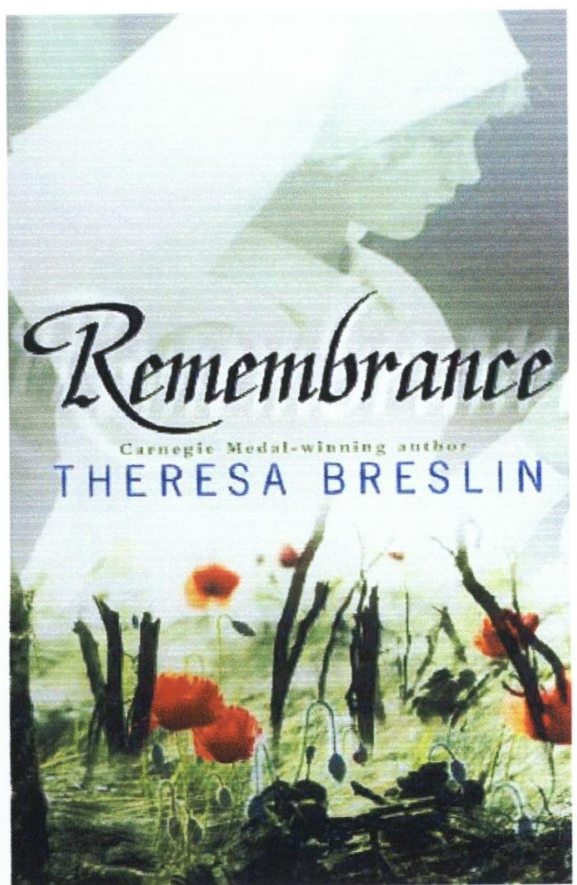

Figure 7: Remembrance

A book that will have to be 'sold' to boys as it features a woman on the cover.

Cover from Remembrance by Theresa Breslin, 2003, reproduced with permission from the publisher, Corgi Children's Books, UK.

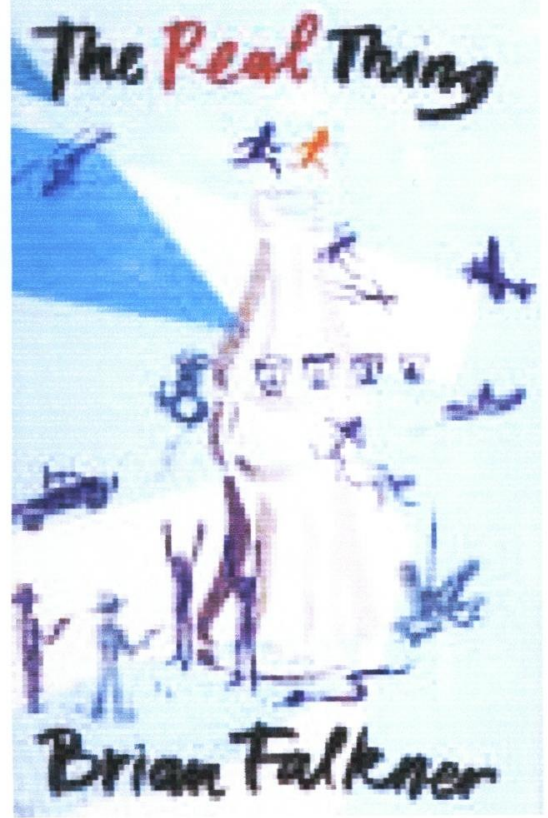

Figure 8: The Real Thing

A cover that is vague, bland and insipid lacking appeal for boys but considered a 'great read' for boys by the participants.

Cover from The Real Thing by Brian Falkner, 2004, reproduced with permission from the publisher, Mallinson Rendel, Wellington. 
Also part of the book packaging is the layout of the book. Three participants from primary, intermediate and high school level commented that line spacing should be 1.5 at the minimum, a clear font that is not too small and not too large to be considered babyish. One participant noted that fully justified margins are unacceptable as the word spacing is uneven making it difficult for the eye to skim across the lines. Two participants commented that books printed on white paper gives a good contrast and larger margins are also preferable. The books should not be too thick but also not too thin, they need substance and 'look like they are for a 10 year old even though they are for a six year old'. One participant suggested that hard back books are too daunting and intimidating for boys as well as being too heavy to carry around. The exception to the rule is of course the Harry Potter books by J.K. Rowling.

Book illustrations were discussed by mainly primary and intermediate schools. It was agreed that illustrations are not necessary but if they are included they must not look babyish. Coloured, line style illustrations or funky, graphic, cartoon style colour illustrations are the preferred style. One participant noted that if the font is small lots of cartoon style illustrations are necessary.

As a participant from a boys-only intermediate and secondary school pointed out:

'Brothers at War' by Jim Rolfe has an old-fashioned photo on the cover which is not good, however the cover contains the word 'war' which is good. A boy will pick it up and read the blurb which must be well written. He will flick through the book and look at the size of the print, illustrations and photos. Only a hard core war enthusiast will take it or those doing a war project - the print is too small and the photos black and white.

Genre was discussed with some of the participants and Question 4 from the questionnaire asked the participants to rank a list of fiction genre according to the boys' preferences. 1 is the most preferred genre, 11 is the least preferred. This is presented in Tables 9 and 10. 


\begin{tabular}{ll}
\hline Rank & Genre \\
1 & Comedy \\
2 & Adventure \\
3 & War / Spy related \\
4 & Crime / Detective \\
5 & Sports related \\
6 & Science fiction / Fantasy \\
7 & Horror / Ghost \\
8 & Animal related \\
9 & School related \\
10 & Poetry \\
11 & Romance / Relationships
\end{tabular}

Table 10: Preferred fiction genre - high schools

\begin{tabular}{ll}
\hline Rank & Genre \\
1 & Science fiction / Fantasy \\
2 & Comedy \\
3 & War / Spy related \\
4 & Adventure \\
5 & Crime / Detective \\
6 & Horror / Ghost \\
7 & Sports related \\
8 & Animal related \\
9 & Romance / Relationships \\
10 & School related \\
11 & Poetry
\end{tabular}

Please note that although the genre are ranked, the margin of difference between the genres especially the first seven is very narrow. For example in the primary + intermediate schools table, both comedy and adventure were both ranked first choice by the same number of schools, however, comedy received one more second choice rank than adventure. It was stressed by three schools that boys read over a wide range and one participant commented that reading interests can be cyclical and 'this year they are not so interested in war stories'. Also, even in a primary school the genre preferences will change. One participant commented that sporty type books are popular for first chapter book readers, or 'trainer wheels books' as one participant termed them. By Year eight, boys like 'busy, complexity, computers, theories and technology' for example the Artemis Fowl series by Eoin Colfer.

At high school level, fantasy is more popular though once again the margins are very narrow, however one participant did comment that she 'finds it hard to keep them in 
fantasy books' and another admitted that fantasy is not her favourite reading and has to glean what information she can from the boys who read them.

As a participant from a boys-only intermediate and secondary school observed:

Today's culture has a lot of fantasy in it. Kid's culture is quite often removed from adult culture. Kids expect adults to read books by Tom Clancy and mothers to read romances. They see themselves as the surreal edgy group. They think their mothers would hate this book, so it is the first good reason to like it.

Three participants commented that it is difficult to predict what boys will like and to be wary of stereotypes.

Content was another consideration which includes the quality of writing and one participant commented that she would not bother buying poorly written material even if it was popular. Three participants commented that the content should not be too wordy or descriptive but short and sharp in the style of David Hill and Chris Ryan. An issue with content in books written for boys is the use of language, violence and at the primary level 'toilet humour'. During the interview nearly all the participants commented on violence from various perspectives. It was agreed that you had to be careful that violence was not needless even in books by respected authors. One participant commented that she does not have Time to Kill by John Grisham in the collection as the first chapter details how to do a gang rape. It also emphasises the need to at least skim read books that go into the collection.

As a participant from a boys-only primary and intermediate school explained:

You need to meet the boys half-way with violence and language in books but maintain the standards expected in the school.

'Toilet humour' is particularly relevant to primary schools with titles like The Adventures of Captain Underpants by Dav Pilkey and The Day my Bum Went Psycho by Andy Griffiths. One participant commented that she expected complaints from parents when Captain Underpants went on the shelves, however it was popular and reading these books gave the boys confidence to move on through the library system and no parents 
complained. Three participants said that they do not have The Day my Bum Went Psycho in their collection considering it a title parents could buy.

As a participant from a co-ed primary school commented:

The dilemma is how far do you go? You don't want to be looking at every book with farts in it as suitable for boys.

Five participants stressed the importance of a strong, current, collection. Weeding is important as old out-of-date books are a big 'turn-off' especially as one participant noted in the boys' favourite areas such as rugby and cars.

Series were mentioned by everyone as an important part of the collection. They are an effective 'hook' to get boys into reading and four participants commented that it is important to get multiple copies of popular series and titles so there are not long waiting lists for them. Tables 11 and 12 which list the most popular books shows the impact series have on boys' reading.

As a participant from a co-ed primary school observed:

Fiction series lead boys into reading more than one book.

\subsubsection{The ten favourite titles in the school library.}

This question from the questionnaire is not a definitive list. It is based on loan statistics and three participants from lower decile schools commented that although boys read books in the library they are reluctant to take them home as the cost of replacing a lost book is too expensive. This may skew the results a little. Graphic novels are not truly represented as one school in the research did not loan graphic novels and in two other schools they needed to be signed out. Also other more substantial non-fiction books such as the Guinness Book of Records are usually not available for loan in school libraries. One participant stated that the most popular books in the library are five non-fiction books about superheroes and they are all not for loan. 
Table 11: Favourite reads - primary and intermediate schools

\begin{tabular}{lll}
\hline Rank & Title & Author \\
1 & Deltora Quest series & Emily Rodda \\
2 & Homible Histories series & Terry Deary \\
3 & Just series & Andy Griffiths \\
4 & Puzzle books & \\
5 & Asterix series & Goscinny and Uderzo \\
6 & Car books in general & \\
7 & The Adventures of Captain Underpants series & Dav Pilkey \\
8 & Hamy Potter series & J.K. Rowling \\
9 & Hatchet series & Garry Paulsen \\
10 & Loamhedge (Redwall series) & Brian Jacques
\end{tabular}

Table 12: Favourite reads - high school

\begin{tabular}{lll}
\hline Rank & Title & Author \\
1 & Tomorrow When the War Began series & $\begin{array}{l}\text { John Marsden } \\
\text { Anthony Horowitz } \\
\text { Emily Rodda }\end{array}$ \\
2 & Alex Rider series & \\
3 & Deltora Quest series & J.K. Rowling \\
4 & Car books in general & Chris Ryan \\
5 & Hamy Potter series & \\
6 & Alpha Force series & J.R.R. Tolkein \\
7 & Sports books especially extreme sports & \\
8 & Lord of the Rings series & Goscinny and Uderzo
\end{tabular}

The 10 favourite books from each school were entered in to a spreadsheet. The titles were rated according to the number of votes for each book and what number in the rank. Once again there was little distinction between the titles for example in the high schools Tomorrow When the War Began was rated first by two schools and fourth by two schools. The Alex Rider series were rated second by two schools, third by one school and seventh by one school. Harry Potter was rated first by one school, third by one school and fifth by two schools.

Many titles for boys, fiction and non-fiction were suggested during the interviews and a list is included in Appendix F. Wayne Mills also has a booklist which groups the titles according the reading level. This list can be found attached to Lorraine Orman's StoryGo-Round web site at: http://homepages.ihug.co.nz/ 1.orman/boysbooks.htm 


\subsubsection{Wayne Martino, an Australian academic, writes that boys should be encouraged to read books that portray males beyond the traditional stereotypes. Contrary to this opinion is the idea that we should just be thankful that boys read anything regardless of how masculinity is portrayed. \\ What is you opinion?}

To illustrate what was meant about portraying males beyond their traditional stereotypes the researcher cited the book Skellig by David Almond, which has won the Whitbread Award and a Carnegie Medal. The male protagonist shows a touching tenderness and the stronger character is the female protagonist. One participant from a boys-only school said Skellig was popular even though she admitted that to a certain extent a culture of male hegemony was promoted in the school, while four other participants considered it more of a girls' book. After these interviews however, one participant said that Skellig had a 'terrible cover, meaningless name and the story is not very good, it is not a strong book'. After this, books by David Hill were cited as an example. Many participants talked around the question and it became clear that there is a great deal more to this question than a simple I agree or I disagree with Martino.

Two participants believed that boys should read anything for a start and once they are reading well they will move on with the encouragement and guidance of the librarian. Another participant supports this stating that Martino's view is fine if the boy is an experienced reader.

As a participant from a co-ed primary and intermediate school explained:

Boys like to read a book and put themselves in the story even if it is science fiction. If the boy is not a confident reader he may not be confident in himself. He would like to read a book where he is the adventurer or hero, he wouldn't like to read a book where he is a house husband or male nurse.

Another participant agreed saying that a masculine hero is important to boys. However, she then commented that the book Breadwinner by Deborah Ellis with a female heroine was read by a teacher to a class and it was a good read so that helped to break the barrier. 
Two participants talked about the need for balance, one giving the example that the Judy Moody books by Megan McDonald have been popular with boys in the school and suggests that you get what they will read but always have other alternatives.

One participant agreed with the opposing viewpoint that boys should be able to read anything as it is important that boys read about all sorts of people.

One participant pointed out that conflict is essential in a book and books need to be realistic. She commented that the skill of a good writer is to acknowledge the world the way it is without the violence becoming gratuitous.

One participant felt that it would be good to encourage them to read beyond the traditional stereotypes but would not reject a book because it had a wrong male stereotype and suggested along with another participant that it is a form of censorship and we should be trying to widen reading not discourage it.

\subsubsection{Elaine Millard has published several books on gender and literacy and says it is very important that school librarians know their collection and know the students so they can suggest to a student a book they would enjoy reading. What do you think of this? Based on what Millard says do you have a book for every student?}

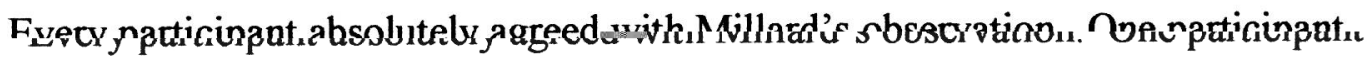
commented that it is not always easy to do as book reading is done in your own time. One participant explained that you cannot read every book when selecting books for the library but you do need to be sure and reasonably familiar with the book by the time it goes on to the shelves. It was also considered important that the librarian gets to know the students and develop a good relationship with them as a book that may suit one boy will not suit another. 
Asked if they had a book for every student, the answer, after some thought, was that they would like to think they would have a book even though it may be non-fiction or a magazine for every student.

\subsubsection{The literature frequently discusses boys' preferences for texts that are analytical and factual. Do you agree with this?}

Table 13 shows boys preferences for fiction and non-fiction according to the participants.

Table 13: Boys' preferences for fiction versus non-fiction

Fiction / non-fiction preference

Prefer fiction

$\%$ of participants

Enjoy reading fiction and non-fiction

$7 \%(n=1)$

Prefer non-fiction

$67 \%(n=10)$

$27 \%(n=4)$

The participant who noted that boys prefer fiction commented that boys like new books and fiction costs less than non-fiction so you can buy more. This was a high school and the observation was also made that NCEA requires students to read extended texts not snippets of information.

The majority agreed that boys did prefer non-fiction more than girls did, however they also enjoyed reading fiction as well. Several participants commented that boys read over a wide range and one participant suggested that boys need to be offered more reading choices. She pointed out that the faction style is popular with boys as it includes actual events and real characters written in the novel format so teachers are happy too.

One participant commented that an increasing number of boys like to read about real people and real happenings, 'they like to learn stuff'. It was also discussed that as boys get older they are more likely to read fiction which may reflect their reading ability and confidence.

The participants who said that boys preferred non-fiction commented that non-fiction is well presented with good graphics. The illustrations break up the text, making it easier to read and it was pointed out that this is a good way to get boys into reading. Four 
participants explained that non-fiction has the advantage of not having to be read progressively through from cover to cover. Boys can dip in and read 'snippets' without losing the context, for example Everything You Need to Know About the World by Simon Elliot and $E=m c^{2}$ : A Biography of the World's Most Famous Equation by David Bodanis allow boys to sift through weird and wonderful facts.

Non-fiction is also preferred because of their interests in such topics as cars, sports, war and weapons.

Comments were also made that boys relate fiction to being made to read, they regard fiction as a 'waste of time' and 'boys don't want to read about feelings'.

As a participant from a boys-only primary and intermediate school explained:

While the new library was being built the library was temporarily housed in a small room. There was not enough room for all the books so non-fiction was put away and only fiction was available. The boys felt like their right arm had been cut off. We battled on but the boys really missed non-fiction and were very happy to be reunited with them in the new library.

\subsubsection{It is frequently commented that boys have more interest in digital resources. Do you use digital books / cd-roms to encourage boys to read?}

Use of digital books and cd-roms to encourage reading was not high. Two participants had digital resources available for children to take home, but they could not use them in the library. Three participants had digital reading resources for children with special needs and three schools were considering them for use in the future. 


\subsubsection{It is commented that comics, magazines and graphic novels are a good way to encourage boys to read. Do you agree with this? Is it reflected in the collection?}

No participant disagreed with this comment and all participants included one or more of these formats in their collection. Sophisticated picture books were also included in the discussion with this question.

$33 \%(n=5)$ included comics in their collection. One participant observed that comics were abused and now only carries the comics of classics such as War of the Worlds. A participant in a primary school did not have the Simpsons comics, although the Simpsons book they have is very popular. She feels parents can buy the comics.

93\% $(n=14)$ included magazines in their collection and the one participant who does not have then is currently investigating them. Magazines were popular and 'well thumbed'.

All the participants have graphic novels in their collection, usually as a special collection. Some of the collections were extensive others consisted of the Asterix series by Goscinny and Uderzo and the Tintin series by Herge. One participant whose collection is limited to the Asterix and Tintin series pointed out that although they are a 'good hook for a lot of kids they are not suitable for SSR'. She may introduce them at a later stage but they are seen as something the students can go to the public library for.

Due to their expense and popularity one participant marked the collection not for loan and another two participants would loan them but the students had to sign them out and return them in person to the librarian, something the students were happy to do.

Graphic novels have proved very popular, drawing boys into the library and appealing to boys who are not normally readers. 
As a participant from a boys-only secondary school observed:

The library is just about full every interval and lunch time, the majority are reading - almost all are reading graphic novels.

The problems with graphic novels are finding titles with suitable content particularly at the primary school level and the poor quality binding of the books.

Scantily clad women were not considered suitable content as well as excessive violence and language.

As a participant from a boys-only intermediate and secondary school remarked:

The boys are supposed to read - not drool.

Another problem reported by five participants is that because the boys 'adore' graphic novels and are reading them so much they are falling apart and require constant mending.

All the participants, including high schools had sophisticated picture books in their collection. Opinion was mixed as to their popularity with boys. Just over half, $53 \%$ $(n=8)$ said that boys do read them. The remaining $47 \%(n=7)$ said that they are not 'cool' to boys and really needed to be outstanding or needed a teacher to push them in class.

As a participant from a co-ed primary and intermediate school noted:

Sophisticated picture books are liked by girls and teachers like to give them to students - but boys don't really want to reflect on it too much.

An example one participant cited of an 'outstanding' sophisticated picture book is Dreamwalker (Figure 9). 


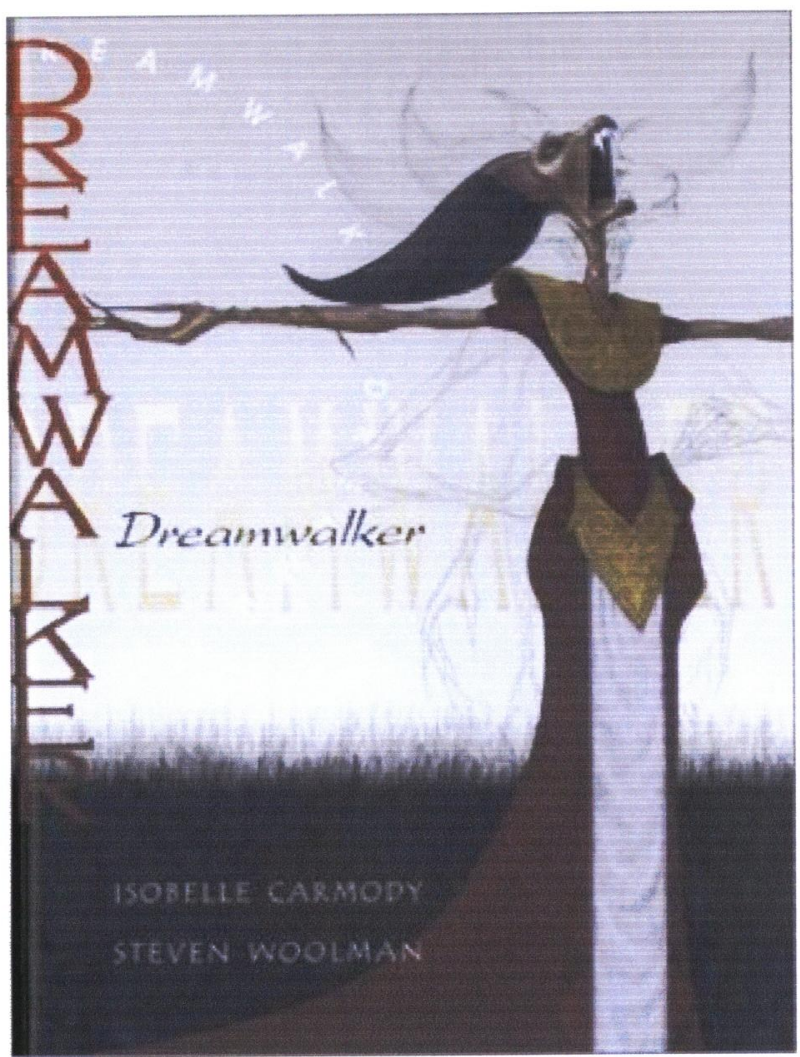

Figure 9: Dreamwalker

Cover from Dreamwalker by Isobelle Carmody and Steven Woolman, 2001, reproduced with permission from the publisher, Lothian Books Melbourne.

One participant said this book is very popular because of the illustrations which supports a view expressed by another participant that sophisticated picture books are used for art as well.

As a participant from a boys-only intermediate and secondary school explained:

The boys do read it but also marvel at the illustrations. The boys do not see it as a picture book it is more like a game or puzzle book and the cover is not bright but edgy. 


\subsection{The school librarian's pedagogical role}

\subsubsection{How and why did you get interested in the issue of boys and reading?}

All the participants cited a combination of reasons that stimulated their interest in boys and reading. $53 \%(\mathrm{n}=8)$ noticed while working in the library that more books were issued to girls than boys and that boys were just not excited by reading and it was affecting their academic achievement.

As a participant from a co-ed intermediate school described:

As a teacher I saw the need. The boys wouldn't take books out or would grab anything from the shelf and then say they had read it when I knew they had not. They would browse the non-fiction or take out the same book all the time. Only 4-5 boys in the class were proper readers the rest did something that approximated reading which was not reading at all.

$40 \%(n=6)$ of the participants reported that as the school became aware of the issue of boys and reading and asked 'how do we address it?' The participants became involved in finding solutions. One participant in a boys-only school comments that it is part of her job description to encourage boys and reading. Teaching staff would also approach librarians asking for help regarding 'their' boys. $33 \%(n=5)$ of the participants stated that they have always had a great interest in children and reading and were motivated to connect boys with books. Two participants became interested through having sons of their own and noticing they were reluctant readers. One participant became interested through attending professional development courses. One participant became aware of the issue when she attended talks given by James Maloney and Paul Jennings. The SLANZA Conference in 2000 also raised awareness of the issue for one participant. 


\subsubsection{Does your school have a written policy regarding boys and reading?}

$20 \%(n=3)$ of the schools surveyed have a written policy regarding boys and reading and one school is in the process of developing a policy. In one private high school the English Department, senior management and the librarian are responsible. In a state intermediate school, senior management and in one private boys' prep school, the English Curriculum Committee is responsible.

Although the majority of the schools did not have a written policy, Literacy Committees existed in a few of the schools and one school responded that although they did not have a written policy there was a definite focus on the issue and it exists in school targets.

\subsubsection{Do you allow other activities, such as music, dvds, games in the library?}

The answer to this question was all yes with the exception of one school. The librarian for this school explained during the interview that she used to have games however the students would leave without putting the games away so games were banned for a while. It then became apparent that the library was still amply filled during breaks and lunch times without the need to offer games.

The librarians noted that the additional activities offered were available during breaks and lunch times only. Scheduled class visits to the library were for research, selecting a book and reading.

Activities offered in the library include: chess in $87 \%(n=13)$ of the schools; other board games such as draughts in $53 \%(n=8)$; cards in $33 \%(n=5)$; jigsaws $33 \%(n=5)$. Other games mentioned were: Cathedral, Battleship, Connect 4, Harry Potter games; War Hammer and games invented by the boys. Dvds, videos and story cds are available at primary and intermediate schools during the winter lunch times in $33 \%(n=5)$ of the schools. Two schools had televisions in the library for special use only, such as during 
the Olympic Games. There was no trend in what was offered by high schools and primary schools, boys-only and co-ed schools and private and state schools.

One school that allows cards and chess in the library will soon ban card playing as the card players are getting too noisy.

Quizzes, aside from the 'Kids' Lit Quiz' which is discussed section 4.2.2.2, were another activity offered. One participant runs a Trivial Pursuit Quiz and two participants are introducing quizzes this year. One participant in a high school has purchased a 'quiz buzzer set' so the library can hold book related quizzes this year. One participant at an intermediate school is building on the successes of the 'Kid's Lit Quiz' and will run science and current events quizzes, a spelling bee and a book club through the library this year.

Drawing was also permitted in the majority of libraries and it was pointed out that boys enjoy copying characters from the book they reading. The most popular books at one school were superhero books such as Batman which were not for loan and kept behind the issue desk. Every lunch time the boys are drawing the characters from the books as well as reading them.

Music, for personal listening was available in three schools and another school library has plans to install listening stations when space and funds permit.

One librarian who has introduced strategic board games in the library this year has noticed boys that who were bored and would come into the library looking for something to do would 'hassle the librarian'. With the introduction of board games this is no longer happening. 


\subsubsection{What other departments or personnel in the school support you in your work to motivate boys' reading?}

This is question 8 from the questionnaire and the results are presented in Table 14 .

Table 14: Departments or personnel who support the librarian motivating boys to read

Department or personnel

English Department

Teachers

Special needs

Principal / Senior staff

Social Sciences

ESOL

Literacy Committee
$\%$ of participants who cited department or personnel

$60 \%(n=9)$

$53 \%(n=8)$

$47 \%(n=7)$

$47 \%(n=7)$

$13 \%(n=2)$

$13 \%(n=2)$

$13 \%(n=2)$

Participants all had at least two other departments or personnel supporting them in their work and although the library works closely with its traditional partner, the English Department, the support of teachers and school management is also important. Special needs includes reading support teachers. In primary and intermediate schools particularly teachers who read aloud to the class were considered very supportive.

As a participant from a co-ed primary and intermediate school observed:

Teachers by reading to the class a variety of authors or genres introduce the kids to books they would not necessarily choose for themselves. This can be hugely successful at 'selling' an author or genre.

However, it was commented that teachers in high schools who use SSR time to catch up on paperwork or read the newspaper are not positive reading role models. Also teachers in primary schools who insist during class library time that children may only borrow and read fiction books were not considered supportive to the librarian. 


\subsubsection{How do you balance being a 'computer guru' and literacy skills educator versus being the 'reading cheer-leader'?}

This question did not raise great divisions, although $40 \%(n=6)$ of the librarians said they were more the reading cheer-leader. It was agreed that the computer is a useful tool for librarians and an aid to finding information.

It was also mentioned that the library without computers would be a 'very, very dull place with an important aspect of the library missing'.

During data collection it became apparent to the researcher that literacy skills and reading are complementary and should not be seen as one winning at the cost of the other.

Eleven participants taught students some form of literacy or library skills. To encourage reading students need to be instructed how to use the library catalogue, the layout of the library, the Dewey system, how to use books - the table of contents, index and glossary and taught some degree of self-help evaluating fiction books to read. As one high school participant stated 'it cannot be assumed that they have learnt these skills at a previous school' and the catalogue and library layout may be quite different. Another participant commented that teaching library skills is a 'good way to get to know the students - it makes it easier to match a boy with a book later'.

\subsubsection{It has been suggested that as digital costs increase and more electronic resources are purchased, spending on fiction will decrease. Can you see this happening in your school?}

The majority, $60 \%(n=9)$ responded no to this question.

As a participant from a co-ed primary and intermediate school commented:

No, not while I'm here.

Many librarians supported this by stating that they had very supportive principals, and worked with good book budgets which were considered essential. One respondent expressed how refreshing it was to work in a supportive environment and acknowledged that it would be difficult to protect the library budget if the importance of the library is 
not recognized. A whole school approach to literacy was another reason cited.

Respondents also argued that non-fiction texts are easier to use with better layout than equivalent digital resources such as EPIC and World Book and you need to be a good reader to use these resources.

The remaining $40 \%(n=6)$ were more cautious with their replies. One could see it happening but not necessarily to fiction, others agreed it was a fine line and jealously protected their budgets. Another commented that indirectly you can be affected as a new computer suite was being built at the school and library funding had not been increased this year. Another respondent has had her budget severely curtailed this year; however, it was not due to increased spending on digital resources.

\subsubsection{How does the school perceive you profile?}

The responses to this question were mainly positive. Four librarians were 'head hunted' by their schools as they had established a reputation in the local area as librarians who can get boys into books. In a few situations the school emphasized the role of the library as the heart of the school and a few held senior positions in the school.

Most of the librarians felt valued by the teachers and were regarded as the person in the school to come to for advice, help and support regarding any aspect of reading.

Keeping the library visible inside and outside the school was also discussed and the need to get teachers on board and looking after their reading needs. Four librarians emphasized the importance of being visible as a person in the school such as helping out on sports day or with drama productions.

However, three librarians talked about the isolation they work in and how the library operated independently from the teaching part of the school. One commented that she was regarded as a support person rather than a professional by the school, although she enjoys a higher profile amongst the school librarian community in New Zealand. 
As a participant from a boys-only secondary school remarked:

The librarian is a bit of a lone person, no one understands what you are doing, why you are doing it and why it is necessary.

The librarians overwhelmingly agreed that they were not 'process' people. Book preparation and mending was mainly done by library assistants, parent help or student librarians. Librarians did their own cataloguing and this process has been sped up considerably with the introduction of the Schools Catalogue Information Service (SCIS). It was considered important to greet a class as they came into the library and spend the library period with them and helping them not behind the desk covering books.

\subsubsection{Many students feel libraries are 'rigid and rule bound'. How do you overcome this but still maintain a certain standard of behaviour?}

The researcher explained at the interview that the label 'rigid and rule bound' was taken from another 1998 MLIS research paper, so it applied to libraries in New Zealand.

It was commented that libraries are changing, if they want customers they need to be more encouraging. Almost all the respondents tolerated noise in the library as long as it did not go over the top.

As a participant from a boys-only secondary school commented:

Boys don't read quietly - they don't even breathe quietly.

Two schools said they now have a classroom for silent study during the lunch hour as the library is too busy and noisy.

Rules relating to respect for each other and property still applied along with the no food or drink in the library rule, however it was generally felt that the students should not be policed but given space within the boundaries set.

As a participant from a co-ed secondary school noted:

Have patience let them be teenagers. 
One primary school librarian school lets the children set the rules, which are then written up on a board, so then the librarian is not making the rules and does not have to tell the children what they are.

Several commented that the library was considered in primary school terms a fun place to be while in high school terms it was considered a place to be. Students were not frightened to come in to the library and saw it as a place to relax and spend some time in. 


\section{Discussion}

\subsection{Strategies to encourage boys to read}

Sustained silent reading (SSR) was used by intermediate and secondary schools in the study, as a whole-school approach to literacy and encouraging reading. It role models reading, as the teachers must also read and provides students with an opportunity for free voluntary reading as opposed to the English class set texts. Coles and Hall (2002), Martino and Pallotta-Chiarolli (2003) and Smith and Wilhelm (2001) all claim that boys are not well suited to the school reading curriculum. 'Boys vernacular literacies give greater emphasis to taking from the text, and to analyzing information rather than analyzing motivation or characterisation' (Coles and Hall, p. 105). During SSR boys can choose to read fiction or non-fiction from the school library.

Krashen (2001b) argues that free voluntary reading results in 'literacy growth' (p. 121). Herda and Ramos (2001) conclude their study of how consistently students read during SSR by stating that it was 'an enjoyable experience for both students and their teacher: for the students, because they appeared to enjoy reading for pleasure' (p. 31). The current study supports both Krashen (2001b) and Herda and Ramos (2001). A study by Methe and Hintze (2003) confirms that teacher role modeling during SSR has a positive effect on students' reading which the current study also supports. An essential requirement for a successful SSR programme is a school library well stocked with reading material boys want to read.

Some participants created reading lists or books lists which are a useful accompaniment to SSR. Reading lists are also used for literacy award schemes and in this study all the reading lists were a mix of fiction and non-fiction. Participants in the current study noted that compiling reading lists takes time and considerable effort to ensure that all reading tastes are catered for and that the lists should be fluid, not static. 
Literacy award schemes, book weeks, author visits and the 'Kid's Lit Quiz' were used by participants in the current study to promote reading awareness and encourage reading for enjoyment. Appendix $\mathrm{G}$ lists references to articles and web sites which have more information on these methods of reading promotion.

Participants used a range of methods to promote books to boys in the library, including booktalks, book displays and photocopies of book covers. While booktalks are a 'direct sell' and participants reported that students queue up for the books afterwards the other methods are less emphatic and are designed to keep the students aware of books as well as adding colour to the library.

Participants in the current study talked about or alluded to the 'home run' book. Ujiie and Krashen (2002) define a 'home run' book as 'a reading experience that readers claim stimulated their initial interest in reading' (p. 36). From their research they state that a home run experience does initiate a greater interest in reading and the current study supports this. Ujiie and Krashen (2002) note that often the greater interest in reading is not sustained and librarians need to keep helping students find a book after the 'home run' experience. The current study supports this, as participants commented that it is important to step in when a student has finished a book or series that they enjoyed reading and help them find another 'just the same'.

In the rationale for this study (section 1.2) it was discussed that previous studies on this topic have tended to be restricted to one school and success encouraging boys to read at one school may not transfer to other schools. This study aimed to build a consensus of ideas from various schools and most of the participants thought that the strategies they used could be applied at any school.

The researcher was aware that measures to encourage boys' reading should not compromise girls (Young 2001) and participants from co-ed schools reported that girls' reading needs have not been neglected and that they have benefited from an increased focus on reading. 


\subsection{Influences on boys' attitudes and behaviour in the library}

Participants did create smaller specific collections in the libraries. The purpose of the special collections was to help students locate what they were interested in quickly and with as little stress and embarrassment as possible. The most common was an 'easy reads' collection. This provided students who were not confident readers with a space in the library where they could comfortably select a book and not feel overwhelmed. Graphic novels were another popular special collection. Schools at all levels had an 'easy reads' collection, however, primary schools tended to have more special collections and used more sign posting and labeling to direct students to areas of interest. Boys-only high schools favoured reading lists, which do give boys a tangible item to search for instead of just looking for 'a book'.

Participants were aware that boys considered reading to be a passive, feminine activity even at primary school level. In the literature this is highlighted by Millard (1997) and Martino (1998) who found that 'reading does not validate a version of masculinity which boys find desirable' (p. 33). Participants in the current study have encouraged male teachers to role model reading as cue to boys that reading and masculinity are compatible. The current study supports what Coles and Hall (2002) term 'gendered reading' (p. 105) meaning that boys are aware they have been labeled 'non-readers'. In reality they mean that they do not read fiction novels as often as females, however, they do read magazines, newspapers and non-fiction. Coles and Hall (2002) and Martino and Pallotta-Chiarolli (2003) comment that boys' disillusionment with English as a subject in school can be partly attributed to the schools lack of recognition for the reading materials they prefer. It is therefore a worthy comment when a senior boy gets up and tells other boys in the school that he is reading the 'Road Code'.

Martino's (1998) article about boys and reading is titled 'Dickheads, Poofs, Try Hards and Losers'. Martino (1998) reports that these terms are labels used by boys who conform to the 'macho norm' (p. 38) to describe boys who read books and like English at school. In the current study the term used was 'library geek' and although participants admitted that they existed, it did not stop other boys coming to the library. Participants 
offered a wide range of reading material, computers, activities such as board games and listing sports teams' results which widens the appeal of the library and makes it acceptable to the 'cool' boys.

Participants stressed the influence of the peer group on boys' reading which supports Simmons (2001) findings. The current study revealed that boys discuss books with each other and recommend books to each other and this does not concur with previous studies. Both Millard (1997) and Gambell and Hunter (2000) point out that girls are more likely to regard reading as a social activity whereas boys are highly unlikely to discuss books with each other. The difference in results could be explained by the current study participants being aware of the value of recreational reading and ensuring the collection has material boys like to read and want to share as a group.

\subsection{Choosing books for boys}

The book as a package was a theme that emerged from the study. The book needs to taken as a whole including the front cover, the blurb, the page layout and format, the illustrations and the number of pages. These criteria are quite specific and the book must never appear too young for the reader.

Participants at primary, intermediate and secondary school levels all discussed the book cover. Book covers were discussed in detail as it seems that it is this first impression of a book that counts for many boys. These findings support those by Brooker (1998) and Sullivan (1998). Sullivan (1998) reports that young adult book covers are a 'hit-or-miss affair with more misses than hits' (p. 180). However, the results of this study did not support this, the participants considered book covers to be more 'hits than misses' and more recent publications of older titles are purchased as they have more appealing book covers. Given the importance boys place on the packaging of a book it would be pertinent for adults who judge children's and young adult book awards to include these details in their evaluation criteria. 
The current study does report that the collection needs regular weeding as old out-of-date books are a 'turn-off' to boys and this supports Millard's (1998) study that boys do not like out-of-date and unappealing books.

The boys' genre preferences correlated quite closely with the Coles and Hall (2002) study in the UK of reading choices among 10,12 and 14 year old boys (see Table 15). The current study divided genre preferences into two categories, primary and intermediate schools in one group and secondary in another group whereas Coles and Hall (2002) did not differentiate between age groups.

Table 15: Preferred Fiction Genre

\begin{tabular}{llll}
\hline Genre & Primary + Intermediate & Secondary Rank & $\begin{array}{l}\text { Hall and Coles } \\
\text { (2002) Rank }\end{array}$ \\
Adventure & Rank & & 1 \\
Animal related & 2 & 4 & 4 \\
Comedy & 8 & 8 & 5 \\
Crime / Detective & 1 & 2 & 7 \\
Horror / Ghost & 4 & 5 & 3 \\
Poetry & 7 & 6 & 10 \\
Romance / Relationships & 10 & 11 & $6=$ \\
School related & 9 & 9 & 9 \\
Science fiction / Fantasy & 6 & 10 & 2 \\
Sports related & 5 & 1 & $6=$ \\
War / Spy related & 3 & 7 & 8
\end{tabular}

A preference for fantasy at the secondary level is the most marked difference between the New Zealand school groups, otherwise the genre have shuffled no more than two places between the school groups. In the Coles and Hall (2002) study a questionnaire was sent to nearly 4,000 boys, obviously a much larger project than the current study. Comparing the New Zealand groups with the Coles and Hall (2002) study, comedy and war and spy stories are more popular in the current study and animal related and romance/relationships less popular, otherwise the rankings are rather similar.

In relation to book covers the current study shows that only animals with a sinister and dangerous dimension such as sharks are acceptable on book covers, cute animals and horses are considered a 'girl's book' and this would also be a consideration in genre. In the current study if romance / relationships had been separated into two different genre categories the result may have been different. In the Coles and Hall (2002) study the 
difference between the first and second genre preferences was quite distinct whereas in the New Zealand groups the distinction was narrow and confirms the participants' observation that boys read widely. Due to the dominance of series in the top 10 book list, if a series of a particular genre is the current favourite then that genre will be the most popular and genre preferences seem to be cyclical.

Ross (1997) reports that reading series books contribute to the development of reading for pleasure and readers in her study explained that 'series books minimized the risk of reading' (p. 20). The current study supports this as all the participants commented that series were an effective way to get boys into reading.

When discussing the content of books, violence, language, the illustrations of the female image and 'toilet humour' were the most common topics that were mentioned by the participants. These topics all embody traditional male hegemony and reach into the theoretical framework for this research, masculinity is a fluid changing construct. Martino (1998) argues boys should read books that portray masculinity diversified while Brozo (2001) argues that we should just be thankful that boys read something. Brozo's view was supported by the participants, arguing for balance and that to restrict the material boys read because of the way masculinity is portrayed is a form of censorship. However, the majority of participants in the current study stated that they, consciously or unconsciously avoided books with gratuitous violence and language supporting Martino's (1998) view.

The participant who reported that Skellig by David Almond which portrays a young boy struggling emotionally, was a popular book in the school, while at the same time acknowledging that traditional male hegemony was to some extent reinforced in the school, was from a private boys' preparatory boarding school and it adds substance to the view expressed by other participants, that a boy needs to be a confident in himself, that is confident in his own masculinity before he will read beyond traditional male stereotypes. Adding to this argument the school which exercised least censorship in reading material was a private boys' secondary school. However, titles by David Hill, also a writer who 
extends beyond traditional male stereotypes, were popular in a range of secondary schools in the study.

Participants who stated that books such as The Adventures of Captain Underpants by Dav Pilkey, containing 'toilet humour' can be bought by parents or that boys could go to the public library to borrow graphic novels were mainly from high decile schools where parents were more likely to buy books for their children and use the public library however, participants from low decile schools did realize that many children would not have the same opportunities. This supports Krashen's (2001) observation that the school library, for many children from low-income families was their sole source of reading material.

All the participants agreed with Millard's (1997) statement, that it is important the librarians know their collection and know their students. The participants did ponder when asked if they had a book for every student and it was probable that they were considering particular students and did they have something for them. The answer that yes they did though it may be a magazine or non-fiction title confirms a theme from the current study that school libraries need to provide a range of reading materials to encourage boys' reading.

The current study supports the Coles and Hall (2002) conclusion that boys are 'hybrid' readers reading from fiction and non-fiction and that they read non-fiction because of their interest in factual information, sports and hobbies. However, Moss's (1999) opinion that boys read non-fiction because they are poor readers is not without substance. Participants did point out that the 'easy reads' were often non-fiction titles with good graphics and the subject matter was likely to appeal to boys who were reluctant readers for example the Dorling Kindersley series about wrestling.

The current study revealed graphic novels were popular, particularly in lower decile secondary schools, attracting boys who may not normally come to the library. This confirms Bruggeman's (1997) and Smith and Wilhelm's (2002) studies that for a generation that have grown up with television, videos and computer games they are visually sophisticated and graphic novels meet this visual sophistication. The content of 
graphic novels was an issue and it is unfortunate that graphic novels with female heroines are often scantily clad and some participants would not buy these books for this reason.

Sophisticated picture books drew a mixed response. Sophisticated picture books reflect gendered reading patterns and they are considered a 'girls book'. Boys who are confident in their own masculinity and reading ability will read more widely including sophisticated picture books.

\subsection{The school librarian's pedagogical role?}

Participants became involved in the issue of boys and reading through their own observation in the library and through schools becoming aware of the issue. It is not clear from the research whether schools became interested because of raised media awareness of the issue or through looking at their own academic results. Schools, once they became aware of the issue involved the librarians to help find a solution to the problem.

The participants permitted games in the library to widen the appeal of the library and attract students who may not necessarily visit the library to read. Once these students were comfortable and familiar with the library environment they might start reading and

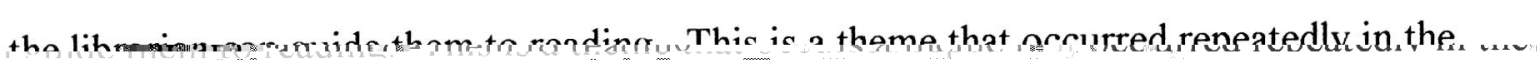

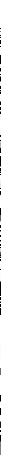


students saw the library as a place to find information for school related activities but it did not provide for their leisure activities and interests. The participants in the current study were aware of this and met curriculum needs and provided for leisure reading and reading about hobbies and interests.

Rafste and Saetre (2004) commented that school librarians were uncertain of their pedagogical role and students felt they could not approach the librarian for help, however, participants in the current study made it clear that they were not 'process librarians' and saw their role as being out in the library working with the students and teachers.

Library budgets were discussed generally with participants, a few mentioned actual figures and it appears that the decile level of a school is not an indicator of library budget levels. The library budget seems to depend on the school's approach to literacy and the importance placed on it, particularly by the principal.

The literature review raised the issue of how a librarian can allows teenagers to be teenagers but still maintain the library as a place for quiet study and research. In the current study basic library rules still applied in all the libraries, no food or drink and respect each other and the school's property. However, the library was seen as a place where students can be with friends, look at books together and lounge about reading. It was noted in the findings that two schools now have a classroom as a quiet study room during lunchtimes.

As part of the data collection while interviewing participants the library and participants were also observed.

A wide range of libraries were visited, from older, smaller libraries to new, bright spacious libraries. Some had space for comfortable seating, such as sofas and cushions as well as tables and chairs. Some displayed student art work which gave the students a sense of identity with the library and some had 'boy appeal' 
posters on the walls. Although a new, spacious library with a comfortable seating area was certainly conducive to reading it was not the most significant factor.

The participants themselves were more significant than the library environment. One participant observed that boys are not as comfortable in the library as girls and the librarian's attitude to boys needs to be 'how can I help you?' not 'what are you doing here?'

All the participants were approachable and reached the boys at their level, setting boundaries for behaviour in the library but also giving space so boys can read and discuss books and magazines as a group. As one participant commented, 'I deal with the boys better now, I enjoy them, they are fun'.

An enthusiasm for reading and an empathy with children and teenagers are certainly an advantage. 


\section{Conclusion}

\subsection{Summary}

The purpose of this research was to investigate how school libraries can encourage boys to read as much of the research into this area has focused on the classroom and teaching staff. The approach has been to gain a greater understanding of the issue rather than develop theories. The aim has been to study what different schools are doing to address the issue, look for themes that emerged from the data and it was regarded as a learning experience by the researcher. The findings have been presented and discussed without evaluating or judging the methods school librarians have used to encourage boys' reading.

The theoretical framework for this study is the theory of masculinity as a social construction formed by the values and influences of the society in which men live. This theory of masculinity is not static but continually evolving.

By analyzing the data and linking them with findings in the related literature, themes have emerged that are important to encouraging boys' reading.

Significant among the themes was the profile of the school librarian who is regarded as a professional by the school staff and has a visible presence in the school. The librarian needs to have a clear understanding of her pedagogical role rather than a librarian who regards her role to be processing books, be approachable and be knowledgeable about children's and young adult books.

A whole school approach to literacy and a good rapport with other staff in the school supports and encourages the librarian. 
The following themes that emerged all relate to S.R. Ranganathan's 'Five laws of library science' cited by Yucht (2001). Written in 1931 they are still relevant more than 70 years later.

\section{Books are for use}

A strong current collection that is weeded regularly. well stocked with fiction, series, non-fiction for their interests and hobbies, magazines and graphic novels. If the librarian has read the book it is easier to 'sell it' to students. A trend that emerged from the research is the increased emphasis on recreational reading as opposed to curriculum based reading especially in the areas of non-fiction and graphic novels.

\section{Every reader his/her book}

Boys are hybrid readers who read fiction and non-fiction over a wide range of topics and there is a broad range of reading levels. School libraries need to have something for everyone. Librarians need to know the students so they can recommend a book they will like to read. The 'home run' read will lead boys into an enjoyment of reading.

\section{Every book its reader}

Librarians as book promoters was a strong theme to emerge. A variety of methods were used to promote books and keep books in the students' minds. Reading the books in the collection made book 'selling' and matching students with books easier.

\section{Save the time of the reader}

Boys can feel intimidated and overwhelmed in the library if they are unsure of where items are located. Information literacy skills are an important aid to reading and creating easy access to books. The library should not be regarded as an 'orienteering course'. 


\section{The library is a growing organism}

Book displays, games in the library, student art work on display, school sports teams' results on the library notice board and cataloguing web sites of interest all create a dynamic library. The library as a growing organism will not be a static environment but fluid and reflect a changing social construct of masculinity.

\subsection{Implications for further research}

This research has investigated how to encourage boys to read from a school librarian's perspective. It would be prudent to conduct further research asking boys what they like to read, what they think of the school library, is it easy to find something you like to read. It would be asking similar questions to those from the research subquestions 2 and 3 but asking the boys the questions instead.

Word count: 24,558 words 


\section{Bibliography}

Alloway, Nola, and Pam Gilbert.1997. Boys and literacy: Lessons from Australia. Gender and Education 9(1) March: 49-61.

Anderson, Gary. 1990. Fundamentals of educational research. London: Falmer Press.

Barry, Warwick and Marion Meiers. 1998. Boys reading: A school case study. [Online] http://www.scotch.vic.edu.au/Curr/English/pdf/boysread.pdf [Accessed 20 May 2005]

Brooker, Dee. 1998. What factors influence 9-11 year-old children's choice of fiction? Talespinner 6 (Sept.): 14-22.

Brozo, William G. 2001. Boys will be boys, or will they? Literacy and masculinities. Reading Research Quarterly 36(3) Jul-Sep: 316-325.

Bruggeman, Lora. 1997. 'Zap! whoosh! kerplow! Build high-quality graphic novel collections with impact. School Library Journal January: 22-27

Burnett, Kathleen and Eliza T. Dresang. 1999. Rhizomorphic reading: The emergence of a new aesthetic in literature for youth. The Library Quarterly 69(4): 421-445.

Chelton, Mary K. 1985. Issues in youth access to library services. School Library Media Quarterly 14 (Fall): 21-25.

Coles, Martin and Christine Hall. 2002. Gendered readings: Learning from children's reading choices. Journal of Research in Reading 25(1): 96-108.

Crawford, Scott. 2002. Graphic novels: An exploration of sequential art. Talespinner 14 (Sept.): 4-13.

Cresswell, John, Ken Rowe and Graeme Withers. 2002. Boys in school and society. Melbourne: Australian Council for Educational Research

Creswell, John W. 2003. Research design: Qualitative, quantitative and mixed methods approaches. Thousand Oaks, Ca: Sage Publications.

Doiron, Ray and Judy Davies. 1996. Reflection and renewal in PEI school libraries [Online] http://www.upei.ca/ raydoiro/html/sch_library_research.html [Accessed 27 May 2005]

Doiron, Ray. 2003. Boy books, girl books: Should we re-organize our school library collections? Teacher Librarian 30(3) Fall: 14-16. 
Dresang, Eliza T. 1999. Graphic books. In Radical change: Books for youth in a digital age New York: H.W. Wilson: 81-103.

Education Review Office. 1999. The achievement of boys. Publications 3 (winter). [Online] http://www.ero.govt.nz/Publications/eers1999/Boys/boys1.htm [Accessed 19 March 2005]

Eyre, Gayner. 2003. Back to basics: The role of reading in preparing young people for the information society. Reference Services Review 31(3): 219-226.

Gambell, Trevor and Darryl Hunter. 2000. Surveying gender differences in Canadian school literacy. Journal of Curriculum Studies 32(5): 689-719.

Gilbert Rob and Pam Gilbert.1998. Masculinity goes to school. St Leonards, NSW: Allen and Unwin.

Goodin, Susie. 2004. Libraries and secondary literacy - the missing link. California School Library Association Journal 27(2) Spring: 13-14.

Gordon-Hall, Heather. 2002. Boys, reading and the school library. Kitimat-Terrace Teacher Research. [Online] http://www.bctf.ca/education/research/backyard/5.pdf [Accessed 27 May 2005]

Gorman, G.E. and Peter Clayton. 2005. Qualitative research for the information professional: A practical handbook. London: Facet Publishing.

Harmon, Charles and Frances B. Bradburn. 1988. Realizing the reading and information needs of youth. Library Trends 37(1) Summer: 19-27.

Hartlage-Striby, Karen. 2001. Girls choose fiction; boys choose non-fiction. Kentucky Libraries 65(4) Fall: 36-40.

Herda, René and Francisco Ramos. 2001. How consistently do students read during sustained silent reading: A look across the grades. California School Library Association Journal 24(2) Spring: 29-31.

Holden, Cathy. 2002. Contributing to the debate: The perspectives of children on gender, achievement and literacy. Journal of Educational Enquiry 3(1): 97-110.

Krashen, Stephen. 1995. School libraries, public libraries and the NAEP reading scores. School Library Media Quarterly 23(4) Summer: 235-237.

Krashen, Stephen. 2001a. Current research: The positive impact of libraries (But have we tapped the potential of the school library?). California School Library Association Journal 25(1) Fall: 21-24. 
Krashen, Stephen. 2001b. More smoke and mirrors: A critique of the National Reading Panel report on fluency. Phi Delta Kappan (Oct.): 119-123.

Kvale, Steinar. 1996. Interviews: An introduction to qualitative research interviewing. Thousand Oaks, Ca:: Sage Publications.

Lance, Keith Curry. 2002. Impact of school library media programs on academic achievement. Teacher Librarian 29(3) Feb.: 29-34.

Leedy, Paul D. 1997. Practical research: Planning and design. New Jersey: Simon and Schuster. Sixth edition

Loertscher, David V. 1990. Reading research and school library media programs. In The research of school library media centres, ed. Blanche Woolls, 49-63. Castle Rock, Co.: Hi Willow Research and Publishing.

Lonsdale, Michele. 2003. Impact of school libraries on student achievement: A review of the research. Melbourne: Australian Council for Education Research

Love, Kristina and Julie Hamston. 2001. Out of the mouths of boys: A profile of boys committed to reading. Australian Journal of Language and Literacy 24(1) Feb. [Online] InfoTrac OneFile Plus/A78787256. [Accessed 13 March 2005]

Martino, Wayne. 1998. 'Dickheads', 'poofs', 'try hards' and 'losers': Critical literacy for boys in the English classroom. English in Aotearoa 35: 31-57.

Martino, Wayne and Maria Pallotta-Chiarolli. 2003. So what's a boy? Addressing issues of masculinity and schooling. Maidenhead, U.K.: Open University Press.

Masters, G. 1997. Literacy standards in Australia. Canberra: Department of Employment, Education, Training and Youth Affairs.

McNicol, Sarah. 2004. Research in school libraries: A survey of practitioners. School Libraries in View 19 (Autumn): 8-11.

Meiers, Marion. 2004. Reading for pleasure and literacy achievements. Australian Council for Educational Research. [Online]

http://www.acer.edu.au/publications/newsletters/Res_Dev/RD12_reading.htm [Accessed 16 March 2005]

Methe, Scott A. and John H. Hintze. 2003. Evaluating teacher modelling as a strategy to increase student reading behaviour. School Psychology Review 32(4): 617-623.

Millard, Elaine. 1997. Differently literate. London: Falmer Press. 
Millard, Elaine. 1998. Balancing the books: Tackling gender differences in reading. In Gender in the secondary curriculum: Balancing the books, eds. Ann Clark and Elaine Millard, 43-59. London: Routledge.

Ministry of Education. 2005. Te Kete Ipurangi. [Online] http://www.tki.org.nz/e/schools/ [Accessed 17 March 2005]

Moffitt, Mary Anne S. and Ellen Wartella. 1992. Youth and reading: A survey of leisure reading pursuits of female and male adolescents. Reading and Research Instruction 31(2): 1-17.

Moss, Gemma. 1999. Boys and non-fiction: Cause or effect? Literacy Today 21 (December).

Mullis, I.V.S. and M.O. Martin, E.J. Gonzalez, A.M. Kennedy. 2003. PIRLS 2001 international report: IEA's study of reading literacy achievement in primary schools. [Online] http://isc.bc.edu/pirls2001i/PIRLS2001_Pubs_IR.html [Accessed 4 June 2005]

Owen, Christopher. 1998. What do teenagers really want? Investigating both sides of young adult services. M.L.I.S. research paper Wellington: Victoria University of Wellington.

Pottorff, Donald, Deborah Phelps-Zientarski and Michelle Skovera. 1996. Gender perceptions of elementary and middle school students about literacy at home and school. Journal of Research and Development in Education 29(4) Summer: 203-211.

Rafste, Elisabeth and Tove P. Saetre. 2004. Bridging gaps - pedagogical investment. Library Review 53(2): 112-118.

Reed, Lynn Raphael. 1999. Troubling boys and disturbing discourses on masculinity and schooling: A feminist exploration of current debates and interventions concerning boys in school. Gender and Education 11(1) March: 93-110.

Ross, Catherine. 1997. Reading the covers off Nancy Drew: What readers say about series books. Emergency Librarian 24(5) May/June: 19-22.

Simmons, Julie. 2001. Raising the standard of boys' achievement in literacy. Spotlights from The Scottish Council for Research in Education. [Online] http://www.scre.ac.uk/spotlight/spotlight81.html [Accessed 18 May 2005]

Slyfield, Helen. 2001. School libraries in New Zealand. New Zealand: National Library.

Smith, Michael W. and Jeffrey D. Wilhelm. 2002. Reading don't fix no chevies: The role of literacy in the lives of young men. Portsmouth, NH: Heinemann. 
Stewart, Kerry. 2001. Keeping it real. Education Gazette. [Online] www.edgazette.govt.nz/articles/show_articles.php?id=6080 [Accessed 4 June 2005]

Taylor, Steven J. and Robert Bogdan. 1998. Introduction to qualitative research methods: A guidebook and resource. New York: John Wiley and Sons Inc.

Sullivan, Ed. 1998. Judging books by their covers: A cover art experiment. Voice of Youth Advocates 21(3) Aug.: 180-182.

Todd, Ross J. 2003. Student learning through Ohio school libraries: A summary of the Ohio research study. [Online] http://www.oelma.org/StudentLearning/documents/OELMAResearchStudy8page.pdf [Accessed 4 June 2005]

Ujiie, Joanne and Stephen D. Krashen. 2001. Comic book reading, reading enjoyment and pleasure reading among middle class and chapter 1 middle school students. [Online] http://www.sdkrashen.com/articles/comicbook/index.html [Accessed 2 June 2005]

Ujiie, Joanne and Stephen Krashen. 2002. Home run books and reading enjoyment. Knowledge Quest 31(1) Sept./Oct.: 36-37.

Usherwood, B and J. Toyne. 2002. The value and impact of reading imaginative literature. Journal of Librarianship and Information Science. 34(1) March: 33-42.

Versaci, Rocco. 2001. How comic books can change the way our students see literature: one teacher's perspective. English Journal 91(2) Nov: 61-67.

Wicks, Jonathan. 1995. Patterns of reading among teenage boys: The reading habits and book preferences of 13-15 year old boys. New Library World 96(1122): 10-16.

Young, Josephine Peyton. 2001. Boys will be boys, or will they? Literacy and masculinities. Reading Research Quarterly 36(3) Jul.-Sept.: 316-325.

Yucht, Alice H. 2001. Guiding principles. Teacher Librarian 28(5) June: 38-39. 


\section{Appendix A}

\section{Request for Participants}

Hello all school librarians,

I am an MLIS student and for my research project I am studying how school libraries can encourage boys to read. Much of the research into the area of boys and reading focuses on the classroom situation, however I feel school libraries can also make a positive contribution as well.

For my research project I would like to study school libraries that have actively encouraged boys to read. The project will be a learning experience; it is appreciated that no school is the same as another and will approach the problem of boys and reading from different angles. The purpose is not to judge which is the best method but to gain insights into what works for different schools and look at the themes and patterns that emerge.

Therefore I would like to hear from school librarians that have promoted reading amongst boys. The ideal would be to sample a wide variety of schools including a range of decile levels; private and state schools; rural and urban schools; co-ed and boys only schools; primary, intermediate and secondary schools.

If you would like to participate please send a reply email to:

mcleananne@student.vuw.ac.nz stating your name and school and that you would like to participate in the research.

Please participate, as your knowledge in this area is valuable and encouraging reading is an area of great potential for school libraries.

Kind regards, Anne McLean 


\title{
Appendix B
}

\section{Covering Letter Sent to Participants}

\author{
$<$ Name $><$ Lastname $>$ \\ $<$ Position $>$ \\ $<$ School $>$ \\ $<$ Address $1>$ \\ $<$ Address $2>$ \\ $<$ City $><$ Postcode $>$ \\ $<$ Date $>$
}

\section{Dear $<$ Name $>$,}

Project Title: Masculinity, reading and the school library: smoothing the abrasive rub

Thank you for agreeing to participate in this research project. This project is looking at how the school library can encourage a more cohesive rapport between boys and reading. I appreciate that you have volunteered your time and knowledge in this rather topical issue. I reiterate that this research project is regarded as a learning experience and schools will approach the issue from a variety of angles creating a rich source of data. The purpose of this project is to look at how different schools are dealing with the issue and tease out emergent themes and patterns. The data collected for this project will not be used for any other purpose.

Enclosed with this letter is a consent form and the preliminary questionnaire. Please read, complete and sign the consent form. The questionnaire will take 15-20 minutes to complete and I will collect both the consent form and questionnaire when I come for the interview.

With your permission the interview will be recorded on audio tape and you will receive a copy of your responses to the questions to read through before the research report is written. The interview will take about one hour. You are free to withdraw from the study before data collection and analysis is complete which is expected to be about 1 May 2005.

All data collected throughout the project will be treated as confidential and held in secure digital and physical environments. Access to the data collected will only be available to the researcher and her supervisor. The research findings published in the report and summary will not identify any individual or specific school library. 
At the conclusion of the project in June 2005 you will receive a summary of the research findings. A copy of the research report will be deposited at the Victoria University of Wellington library. Once the report is completed all questionnaires and transcribed interviews will be destroyed and all interview tapes will be electronically erased.

Victoria University requires that all research conducted under its auspices be approved by the Human Ethics Committee which has been obtained for this project.

If you require any further information regarding this project please feel free to contact myself by phone on 095802060 or by e-mail at mcleananne@student.vuw.ac.nz. You can also contact my supervisor, Dr Chern Li Liew, School of Information Management, Victoria University of Wellington, PO Box 600, Wellington, phone 044635213 . I look forward to talking with you on $<$ Interviewdate $>$ at $<$ Time $>$ about this timely and interesting topic.

Yours truly

Anne McLean 


\section{Appendix C}

\section{Consent Form for Participants}

Project Title: Masculinity, reading and the school library: smoothing the abrasive rub

Please read, sign and return this consent form with the questionnaire.

1. I have received and understood the purpose of this study. I understand that the information I provide will not be used for anything other than this purpose.

2. I understand that any information I give will be kept confidential to the researcher and her supervisor.

3. I understand that I am free to withdraw from this study (before data collection and analysis is complete, approximately 1 May 2005) and no explanation is necessary.

4. I understand that neither my name nor the name of my school will appear in the published report

5. I give permission for the interview to be tape-recorded.

6. I understand that I will have the opportunity to read my interview responses before the research report is written.

7. I understand that the questionnaire, tape-recorded interview and transcribed data will be held in a secure place during the study. I understand that once the report has been published the transcribed data and questionnaire will be destroyed and the tape-recorded interview will be electronically cleaned.

8. I understand a copy of the published report will be held in the Victoria University of Wellington Library.

9. I will receive a summary of the report once the report has been published.

10. I agree to participate in this research.

Signed:

Name: 


\section{Appendix D}

\section{Questionnaire}

Masculinity, reading and the school library: smoothing the abrasive rub. or How school libraries can encourage boys to read

\section{Questionnaire}

1. How and why did you get interested in the issue of boys and reading?

2. Does your school have a written policy regarding boys and reading?
$\bigcirc \quad$ Yes
$\square$ please answer the rest of the question
No
$\square$ please go on to the next question

Who has been responsible for developing this policy? 
3. Do you collect fiction specifically for boys?
Yes
$\square$ please answer the rest of the question
No
$\square$ please go on to the next question

What is important to you when selecting fiction for boys? List below the most important considerations.

4. Below is a list of fiction genre types. Please rank them according to the boys' preferences at your school.

$\square$ Rank them from 1 through to 5, 1 = the most preferred, $5=$ the least preferred.

\section{Genre Type}

Adventure

Animal-related

Comedy

Crime/detective

Horror/ghost

Poetry

Romance/relationships

School-related

Science fiction/fantasy

Sports-related

War/spy-related
Rank

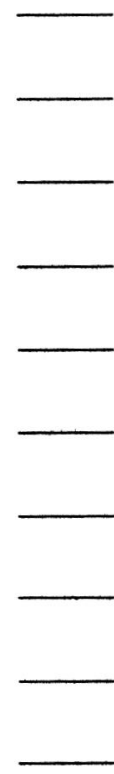


5. List below what you think the most important considerations are when encouraging boys to read.

6. Could you list below (an estimate is fine) the boys' ten favourite titles in your school library. The titles can be fiction (F) or non-fiction (N/F).

Title

1.

2.

3.

4.

5.

6.

7.

8.

9.

10. 
7. Do you allow other activities, such as music, DVDs, games in the library?

\begin{tabular}{|c|c|}
\hline Yes & please answer the rest of the question \\
\hline No & $\square$ please go on to the next question \\
\hline
\end{tabular}

Could you please describe the other activities that are allowed in the library?

8. What other departments or personnel in the school support you in your work to motivate boys' reading?

Please post the completed questionnaire and signed consent form in the pre-paid envelope provided. Thank you, I look forward to talking with you soon. 


\section{Appendix E}

\section{Interview Questions}

PART A Strategies and initiatives school libraries have developed to encourage boys to read.

1. Did you develop a strategy to encourage boys' reading or was it a gradual process that grew, or a way of thinking?

Discuss the most important considerations for encouraging boys to read from questionnaire.

2. What have been the results of the strategy/process/way of thinking?

3. Are there plans to develop it further?

4. Do you think this would be successful in other schools?

5. What other organisations did you seek guidance and support from? 

library selecting and reading $a$ book.

1. What methods are used to help students find a book?

2. Many boys perceive reading especially if their fathers do not read books to be a feminine activity and therefore not something males do. In a library that is usually staffed by women how do you overcome this negative perception?

3. Generally speaking boys would prefer to be playing sports, being with friends, watching $T V$, or on the computer rather than reading.

How do you overcome this?

4. What other influences do you see as important on boys and reading?

5. It has been observed that boys require more guidance than girls selecting a book to read and during set reading times in the library they are more likely to come without a book or would re-read a book as it is a safer option than selecting a new book.

Based on experience in your library what do think? 
1. Discuss from the questionnaire the most important considerations when choosing fiction for boys.

2. Wayne Martino, an Australian academic, writes that boys should be encouraged to read books that portray males beyond the traditional stereotypes. Contrary to this opinion is the idea that we should just be thankful that boys read anything regardless of how masculinity is portrayed. What is your opinion?

3. Elaine Millard has published several books on gender and literacy and says it is very important that school librarians know their collection and know the students so they can suggest to a student a book they would enjoy reading. What do you think of this?

4. The literature frequently discusses boys' preferences for texts that are analytical and factual.

Do you agree with this?

5. It is frequently commented that boys have more interest in digital resources. Do you use digital books / CD-Roms to encourage boys to read?

6. It is commented that comics, magazines and graphic novels are a good way to encourage boys to read.

Do you agree with this? 
1. How do you balance being a 'computer guru' versus being the 'reading cheer leader'?

2. It has been suggested that as digital costs increase and more electronic resources are purchased spending on fiction will decrease.

Can you see this happening in your school?

3. How does the school perceive you profile?

4. Many students feel libraries are 'rigid and rule bound'.

How do you overcome this but still maintain a certain standard of behaviour? 


\section{Appendix F}

\section{Titles and Authors Cited by Participants}

Primary and Intermediate Schools

\section{Title}

Alpha Force series

2much2do

Agent $Z$

Alex Rider series

Animal Crackers

Artemis Fowl series

Asterix series

Aussie Bites series

Aussie Chomps series

Bone: Graphic novel

Boyz Rule!

Breadwinner

Adventures of Captain Underpants series

Chain Gang series

Day After Forever

Deltora Quest series

Diamond Brothers trilogy

Diary series

Dirt Bikes

Everything You Need to Know About the World

Explorers Wanted series

Extreme series

Fast Track Classics series

French Confection series

Graffix series: Graphic novels

Hatchet series

\author{
Author or Publisher \\ Chris Ryan \\ Vince Ford \\ Mark Haddon \\ Anthony Horowitz \\ Narinder Dhami \\ Eion Colfer \\ Goscinny and Uderzo \\ Published by Puffin Books, Australia \\ Published by Puffin Books, Australia \\ Jeff Smith
}

Felice Arena

Deborah Ellis

Dav Pilkey

Robin Lawrie

Erin Skiffington

Emily Rodda

Anthony Horowitz

Published by Kangaroo Press, Australia

Matt Christopher Sports Classics

Simon Elliot

\section{Simon Chapman}

Published by Scholastic, Auckland

Pauline Francis

Anthony Horowitz

Publisher: A and C Black, London

Gary Paulsen 
Hobbit: Graphic novel

Holes

Horrible Histories series

Horrid Henry

I Spy series

Jiggy McCue series

Just series

Kiwi Bites series

Look and Find series

Marvin Redpost

Maxx Rumble series

Mr Majeka

Northern Lights

Poison

Loamhedge (Redwall) series

Secret Assault series

Sport Max series

The Fugitives

The Mighty Crashman

The Secrets of Droon series

The Subtle Knife

The War Diaries of Alistair Fury series

Tintin series

Tomorrow When the War Began Series

Too Cool series

Unfortunate series

Wayside School series

Where's Wally series

World of Adventure series

Xtreme Team series

Wayside School series
J.R.R. Tolkein

Louis Sachar

Terry Deary

Francesca Simon

Published by Scholastic, New York

Michael Lawrence

Andy Griffiths

Published by Puffin Books, Auckland

Published by Publications International, USA

Louis Sachar

Michael Wagner

Humphrey Carpenter

Phillip Pulman

Chris Wooding

Brian Jacques

Jim Eldridge

Published by Scholastic, Auckland

Alex Shearer

Jerry Spinelli

Tony Abbott

Phillip Pulman

Jamie Rix

Herge

John Marsden

Phil Kettle

Lemony Snicket

Louis Sachar

Martin Handford

Gary Paulsen

Matt Christopher Sports Classics

Louis Sachar 
Secondary Schools

Title

Alpha Force

9/11: Graphic Novel

Alex Rider series

Asterix series

The Big Bang

Bone: Graphic novel

Calvin and Hobbs: Graphic novel

Coming Back

Cracking Codes

Deltora Quest series

Dreadful Acts

Dreamwalker

$\mathrm{E}=\mathrm{mc} \mathrm{c}^{2}$

Eragon

Eyewitness series

Far Side

Groo and Rufferto: Graphic novel

Harry Potter series

Henry and the Flea

Hobbit : Graphic novel

Holes

Lord of the Rings series

Maus: Graphic novel

Midnight for Charlie Bone

Mortal Engines

Loamhedge (Redwall) series

See Ya Simon

The Dragon Chronicles

The Real Thing

The Thief

Thunder Road

Tintin series

\section{Author or Publisher}

Chris Ryan

Will Eisner

Anthony Horowitz

Goscinny and Uderzo

Paul Parsons

Jeff Smith

Bill Watterson

David Hill

Diana Kimpton

Emily Rodda

Philip Ardagh

Isobelle Carmody

David Bodanis

Christopher Paolini

Dorling Kindersley

Gary Larsen

Sergio Aragones

J.K. Rowling

Brian Falkner

J.R.R. Tolkein

Louis Sachar

J.R.R. Tolkein

Art Spiegelman

Jenny Nimmo

Philip Reeve

Brian Jacques

David Hill

Malcolm Saunders

Brian Falkner

Megan Whalen Turner

Ted Dawe

Herge 


\section{Appendix G}

A list of journal articles and web sites that have information about the Kid's Lit Quiz, organizing book weeks, author visits and reading incentive schemes.

\section{Journal Articles}

- The ABC's of marketing by Kathy Schrock from the School Library Journal, November 2003, volume 49, issue 11.

Available online from MasterFILE Premier, document accession Number: 11297477.

- Promoting reading to middle school students: May the booktalks contimue by Betty W. Stone from the Book Report, January / February 2000, volume 18 issue 4. Available online from MasterFILE Premier, document accession number: 2656887.

- All aboard for Book Week by Sandy Meagher, from Teaching PreK-8, November / December 2004, volume 35, issue 3.

Available online from MasterFILE Premier, document accession number: 14765963.

- Kohia Terrace School Literacy Awards Scheme: A model for encouraging recreational reading by Bronwyn Fox from Magpies, September 2003, volume 18 , issue 4 .

- Nothing for boys? The Liston experience by Lois Huston from Magpies, May 2005 , volume 20 issue 2 .

Web sites

- The Kid's Lit Quiz: http://www.kidslitquiz.com/

- Nancy Keane Booktalks: http://nancykeane.com/booktalks 